\title{
Cystathionine- $\gamma$-lyase promotes the metastasis of breast cancer via the VEGF signaling pathway
}

\author{
LUPENG WANG $^{1 *}$, HAIMEI SHI ${ }^{2 *}$, YA LIU ${ }^{1}$, WEIYUAN ZHANG ${ }^{1}$, XIAOFANG DUAN $^{1}$, \\ MING LI ${ }^{1}$, XIAOYAN SHI ${ }^{1}$ and TIANXIAO WANG ${ }^{1,3}$ \\ ${ }^{1}$ School of Pharmacy, Henan University, Kaifeng, Henan 475004; \\ ${ }^{2}$ Anesthesiology Department, The First Affiliated Hospital, Zhengzhou University, Zhengzhou, Henan 450052; \\ ${ }^{3}$ Joint International Research Laboratory of Food \& Medicine, Henan University, Kaifeng, Henan 475004, P.R. China
}

Received January 31, 2019; Accepted May 31, 2019

DOI: 10.3892/ijo.2019.4823

\begin{abstract}
The present study aimed to provide data to support the association between cystathionine- $\gamma$-lyase (CSE) and breast cancer metastasis. Reverse transcription-quantitative polymerase chain reaction, immunohistochemistry and western blot analysis were used to detect the mRNA and protein expression levels of CSE in human breast cancer tissues and cells. MTS and 5-ethynyl-2'-deoxyuridine assays were used to assess cell viability and proliferation. Scratch wound and Transwell assays were conducted to determine cell migration and invasion. In addition, hydrogen sulfide determination was performed using the methylene blue method. The expression of CSE was upregulated in samples from patients with breast cancer that also exhibit lymph node metastasis, and in grade III and readily metastatic breast cancer cell lines. The proliferation, migration and invasion of breast cancer cells were examined in the present study, and tumor metastasis was observed in nude mice. The function of CSE in breast cancer metastasis depends on the vascular endothelial growth factor (VEGF) signaling pathway, a key mediator of angiogenesis that is crucial for the development and metastasis of tumors. CSE positively regulated the expression of VEGF and increased the levels of certain key proteins in the VEGF pathway, including the phosphoinositide (PI3K)/protein kinase B (AKT) pathway [PI3K, Akt and phosphorylated (p)Akt], focal adhesion kinase (FAK)-paxillin pathway (FAK and paxillin) and rat sarcoma (Ras)-mitogen-activated protein kinase pathway [Ras, rapidly accelerated fibrosarcoma, extracellular signal-regulated kinase (ERK)1/2 and pERK1/2]. Furthermore,
\end{abstract}

Correspondence to: Professor Tianxiao Wang or Dr Xiaoyan Shi, School of Pharmacy, Henan University, 1 Jinming Road, Kaifeng, Henan 475004, P.R. China

E-mail:wtx1975@126.com

E-mail: shisheep@126.com

*Contributed equally

Key words: cystathionine- $\gamma$-lyase, vascular endothelial growth factor, breast cancer, metastasis the novel CSE inhibitor I157172 possessed antiproliferative and anti-metastatic activities in early MDA-MB-231 metastatic breast cancer cells via inhibition of the VEGF signaling pathway, which further confirmed the role of CSE in breast cancer metastasis. Overall, these data demonstrate for the first time, to the best of our knowledge, that the functions of CSE in breast cancer metastasis are associated with the VEGF signaling pathway.

\section{Introduction}

Metastasis is the most life-threatening characteristic of cancer; it is a multi-step process that causes cancer cells to spread throughout the body (1). Malignant tumors containing both neoplastic cells and non-neoplastic cellular components possess the ability to metastasize due to interactions between the cellular elements of the tumor with the extracellular matrix (ECM) (2,3). Numerous growth factors and their receptors, in addition to angiogenic factors, are involved in the process of cancer metastasis (4).

Breast cancer is the most common malignant tumor in women worldwide, and recurrence and metastasis remain the leading causes of mortality in patients with this disease. However, there are numerous treatment modalities currently available (5), which demonstrates the need for novel therapeutic targets and agents for the treatment and prognosis of breast cancer.

Hydrogen sulfide $\left(\mathrm{H}_{2} \mathrm{~S}\right)$, as the third gasotransmitter signaling molecule alongside nitric oxide (NO) and carbon monoxide (CO), functions as a potent angiogenic factor $(6,7)$ and is involved in a number of other physiological processes (8-11). A previous study also revealed endogenously produced $\mathrm{H}_{2} \mathrm{~S}$ in the angiogenic process (12). The pharmacological inhibition and silencing of the enzymes involved in $\mathrm{H}_{2} \mathrm{~S}$ synthesis attenuates the angiogenic properties of endothelial cells, including proliferation, migration and formation of a tube-like structure network. By contrast, the enhanced production of $\mathrm{H}_{2} \mathrm{~S}$ by substrate supplementation or the overexpression of $\mathrm{H}_{2} \mathrm{~S}$-producing enzymes leads to enhanced angiogenic responses in cultured endothelial cells and upregulates the expression of vascular endothelial growth factor (VEGF), a key angiogenic factor. 
Cystathionine- $\gamma$-lyase (CSE), one of key enzymes of the trans-sulfuration pathway, catalyzes endogenous $\mathrm{H}_{2} \mathrm{~S}$ production (13). Studies have demonstrated that endogenous $\mathrm{H}_{2} \mathrm{~S}$ produced by CSE can promote the proliferation of human cancer cells $(14,15)$. A previous study revealed that high expression levels of CSE promoted the progression of breast cancer in association with the STAT3 signaling pathway (16). Therefore, the CSE/ $\mathrm{H}_{2} \mathrm{~S}$ system serves an important role in the progression of cancer.

It is already well established that tumor metastasis is closely associated with tumor angiogenesis. Based on the function of endogenous $\mathrm{H}_{2} \mathrm{~S}$ promoting angiogenesis and the role of the $\mathrm{CSE} / \mathrm{H}_{2} \mathrm{~S}$ system in tumors, it is possible that the $\mathrm{CSE} / \mathrm{H}_{2} \mathrm{~S}$ system may be involved in the metastasis of a tumor. Therefore, the aim of the present study was to elucidate the roles and regulatory mechanisms of CSE in the metastasis of breast cancer cells. In addition, the effects and mechanisms of novel CSE inhibitors against breast cancer metastasis were investigated. The present study reveals novel avenues for investigations into useful therapeutic targets and agents for the treatment of breast cancer.

\section{Materials and methods}

Patient samples, animals and cell lines. A total of 30 breast cancer tissues and adjacent non-tumor tissues were obtained from patients at Huaihe Hospital (Kaifeng, China). All patients (age range, 37-70 years; no smoking history available) had a non-specific type of invasive breast cancer (10 cases of grade II and 20 cases of grade III breast cancer; 13 cases of non-lymph node metastasis; and 17 cases of lymph node metastasis). $\mathrm{Balb} / \mathrm{c}$ nude mice (specific pathogen-free; female; 4-6 weeks) weighing 18-22 g were supplied by Beijing Weitong Lihua Experimental Animal Technology Co., Ltd. The mice were allowed free access to food and water, and were housed in an environment with constant temperature $\left(24 \pm 1^{\circ} \mathrm{C}\right)$, humidity (50-70\%), ventilation rate $(10-20$ times/h), noise $(<40 \mathrm{db})$ and working illumination $(250 \mathrm{~lx})$ under a 12 -h light/dark cycle. Drinking water, food and experimental supplies were sterilized and disinfected. The present study was approved by the Ethics Committee at the Medical School, Henan University (Kaifeng, China). Early metastatic breast cancer cells (MDA-MB-231), non-metastatic breast cancer cells (MCF7) and mammary epithelial cells (Hs578Bst) were obtained from the American Type Culture Collection, and cultured in Dulbecco's modified Eagle's medium (DMEM) supplemented with $10 \%$ fetal bovine serum (Zeta-life) in a $37^{\circ} \mathrm{C}$ incubator with $5 \% \mathrm{CO}_{2}$.

Immunohistochemistry. Immunohistochemical staining of the surgical specimens from patients with breast cancer was performed in serial sections (average section area, $1 \times 1 \mathrm{~cm}$ ) of formalin-fixed, paraffin-embedded tissues $(0.2 \mathrm{~cm}$-thick). Following deparaffinization, the slides were placed in $0.01 \mathrm{M}$ citrate salt solution (Epitope Retrieval Solution) and heated in a microwave oven for $7 \mathrm{~min}$. Following cooling and washing with PBS, endogenous peroxidase was blocked with $30 \%$ $\mathrm{H}_{2} \mathrm{O}_{2}$ for 10 min and incubated with 5\% BSA (Sigma-Aldrich; Merck KGaA) to block non-specific binding of antibodies. The slides were then incubated with CSE primary antibody (cat. no. 60234-1-Ig; 1:100; ProteinTech Group, Inc.) at $4^{\circ} \mathrm{C}$ overnight, followed by incubation with biotin-conjugated secondary antibody (cat. no. SA00004-1; 1:1,000; ProteinTech Group, Inc.) and streptavidin horseradish peroxidase for $10 \mathrm{~min}$ each. Antigen-antibody complexes were visualized in 3,3'-diaminobenzidine, and cells were subsequently stained with hematoxylin and dehydrated, and images were captured with a laser confocal microscope (LSM710; Carl Zeiss AG). Unless otherwise specified, all incubation steps were performed at room temperature.

Western blot analysis. Proteins were extracted from human breast cancer and paracancerous tissues, the MCF7 and MDA-MB-231 human breast cancer cells, CSE-knockdown MDA-MB-231 cells [MDA-MB-231 cells transfected with CSE small interfering RNA (siRNA) for $48 \mathrm{~h}$, or treated with 10, 20 and $30 \mu \mathrm{M}$ I157172 for $24 \mathrm{~h}$, with CSE-knockdown MDA-MB-231 cells transfected with the CSE plasmid for $48 \mathrm{~h}]$ and normal mammary epithelial cells (Hs578Bst) using radioimmunoprecipitation assay buffer $[50 \mathrm{mM}$ Tris- $\mathrm{HCl}$ ( $\mathrm{pH} 8.0$ ), $150 \mathrm{mM}$ sodium chloride, $1.0 \% \mathrm{NP}-40$, $0.5 \%$ sodium deoxycholate and $0.1 \%$ SDS] supplemented with $10 \mu \mathrm{g} / \mathrm{ml}$ phenylmethylsulfonyl fluoride (Sigma-Aldrich; Merck $\mathrm{KGaA}$ ). The samples were then centrifuged at $12,000 \mathrm{x} \mathrm{g}$ for $10 \mathrm{~min}$ at $4^{\circ} \mathrm{C}$, and protein concentration was determined using the Bicinchoninic Acid Protein Quantitative kit (Solarbio Science \& Technology Co., Ltd.). The protein samples $(40 \mu \mathrm{g})$ were separated by SDS-PAGE $(10 \% \mathrm{gel})$ and transferred onto polyvinylidene difluoride membranes (EMD Millipore) at $70 \mathrm{~mA}$ for $2 \mathrm{~h}$ at $4^{\circ} \mathrm{C}$. The membrane was then blocked in 5\% fat-free milk for $2 \mathrm{~h}$ at room temperature, and probed with specific primary antibodies against CSE, matrix metalloproteinase (MMP)-2, MMP-9, VEGF, phosphatidylinositol 3-kinase (PI3K), protein kinase B (Akt), phosphorylated (p)Akt, focal adhesion kinase (FAK), paxillin, rat sarcoma (Ras), rapidly accelerated fibrosarcoma (Raf), extracellular signal-regulated protein kinases (ERK)1/2, and pERK $1 / 2$ at $4^{\circ} \mathrm{C}$ overnight. Following incubation with the secondary antibody for $2 \mathrm{~h}$ at room temperature, the proteins were visualized using an EasyBlot Enhanced Chemiluminescence kit (Sangon Biotech Co., Ltd.) and detected using a FluorChem Q Multifluor system (ProteinSimple). GAPDH was used as a loading control. The primary antibodies were as follows: CTH (CSE) mouse monoclonal antibody (1:100; cat. no. sc-365382; lot no. LL2619) from Santa Cruz Biotechnology, Inc.; MMP-2 rabbit polyclonal antibody (1:1,000; cat. no. 4022), MMP-9 rabbit polyclonal antibody (1:1,000; cat. no. 3852), Akt rabbit monoclonal antibody (1:1,000; cat no. 4685), pAkt rabbit monoclonal antibody (1:1,000; cat no. 4060), Ras rabbit monoclonal antibody (1:1,000; cat no. 3965), p44/42 MAPK (Erk1/2) rabbit monoclonal antibody (1:1,000; cat. no. 4695) and $\mathrm{pErk} 1 / 2$ rabbit monoclonal antibody (1:1,000; cat. no. 4376) from Cell Signaling Technology, Inc.; VEGF rabbit polyclonal antibody (1:1,000; cat. no. 19003-1-AP), PI3Kp110( $\beta$ ) rabbit polyclonal antibody (1:1,000; cat. no. 20584-1-AP), FAK rabbit polyclonal antibody (1:1,000; cat. no. 12636-1-AP), paxillin rabbit polyclonal antibody (cat. no. 22172-1-AP) and RAF rabbit polyclonal antibody (cat. no. 551140-1-AP) from ProteinTech Group, Inc.; and GAPDH mouse monoclonal antibody (1:1,000; cat. no. AG019) from Beyotime Institute of Biotechnology. The secondary antibodies were as follows: Horseradish peroxidase-conjugated goat anti-mouse (1:10,000; cat. no. SA00001-1) and horseradish peroxidase-conjugated 
goat anti-rabbit (1:10,000; cat. no. SA00001-2) from ProteinTech Group, Inc. The quantitative differences were determined using Image-J2x software (Rawak Software, Inc.).

RNA extraction and reverse transcription-quantitative polymerase chain reaction ( $R T-q P C R)$ analysis. Total RNA was extracted from the human breast cancer and adjacent non-tumor tissues, human breast cancer cells and mammary epithelial cells using TRIzol ${ }^{\circledR}$ reagent (Invitrogen; Thermo Fisher Scientific, Inc.), and genomic DNA elimination and cDNA synthesis were performed using PrimeScript ${ }^{\mathrm{TM}}$ RT Reagent kit (RR047A; Takara). qPCR was performed using SYBR Premix Ex Taq II, and the PikoReal ${ }^{\text {TM }}$ Real-Time PCR system (Thermo Fisher Scientific, Inc.) was used to measure mRNA expression. The reaction conditions were as follows: Initial template degeneration, $95^{\circ} \mathrm{C}$ for $30 \mathrm{sec}$; followed by 40 cycles at $95^{\circ} \mathrm{C}$ for $5 \mathrm{sec}, 55^{\circ} \mathrm{C}$ for $30 \mathrm{sec}$ and $72^{\circ} \mathrm{C}$ for $30 \mathrm{sec}$; and a final step at $60^{\circ} \mathrm{C}$ for $30 \mathrm{sec}$. The reactions for each sample-primer set were performed in triplicate. Relative quantification analysis was performed using the comparative $2^{-\Delta \Delta \mathrm{Cq}}$ method (17). All data were normalized to the internal control GAPDH. The primer sequences were as follows: CSE, forward, 5'-CCCATCTCACTGTCCACCAC-3' and reverse, 5'-GTGCTGCCACTGCTTTTTCA-3'; length, 115 bp; GAPDH, forward, 5'-CTCTGCTCCTCCTGTTCGAC-3' and reverse, 5'-ACCAAATCCGTTGACTCCGA-3'; length, 109 bp.

siRNA and plasmid transfection, and construction of stable CSE-knockdown MDA-MB-231 cells. For knockdown in the MDA-MB-231 cells, MDA-MB-231 cells were cultured in 6 -well plates until they reached $30-40 \%$ cell confluence. The cells were transfected with scrambled siRNA (Sc siRNA) or specific siRNA against human CSE using Lipofectamine ${ }^{\mathrm{TM}}$ 2000 (both from Invitrogen; Thermo Fisher Scientific, Inc.) at $37^{\circ} \mathrm{C}$ for $48 \mathrm{~h}$. The medium was replaced at $6 \mathrm{~h}$ post-transfection, and the silencing efficiency was determined via western blotting at $48 \mathrm{~h}$ post-transfection. The primer sequences for the CSE-specific siRNA were as follows: Forward, 5'-GGUUUAG CAGCCACUGUAAdTdT-3' and reverse, 5'-UUACAGUGGCU GCUAAACCdTdT-3'; the primers were designed to target the open reading frame region of CSE mRNA.

For overexpression in MDA-MB-231 cells, the MDA-MB-231 cells were cultured in 6-well plates until they reached $80-90 \%$ confluence. The cells were then transfected with pCMV-EGFP vector and pCMV-EGFP-hCSE (GeneChem Co., Ltd.) using Lipofectamine 2000, according to the manufacturer's protocol. The cells were exposed to fresh medium at $6 \mathrm{~h}$ post-transfection and the overexpression efficiency was determined via western blot analysis at $48 \mathrm{~h}$ post-transfection.

Fortheconstruction of stableCSE-knockdownMDA-MB-231 cells, the MDA-MB-231 cells $\left(5 \times 10^{4}\right)$ were seeded into 12 -well plates. After $24 \mathrm{~h}, 500 \mu \mathrm{l}$ of the medium was replaced with medium containing $50 \mu 1$ lentiviral packaging CSE short hairpin (sh)RNA (hU6-MCS-CBh-gcGFP-IRES-puromycin-CSE shRNA $\left(1 \times 10^{7} \mathrm{TU} / \mathrm{ml}\right)$. After another $10 \mathrm{~h}$, all the medium was removed and replaced with normal medium. After $72 \mathrm{~h}$, puromycin was added to screen and obtain the stable CSE-knockdown MDA-MB-231 cells.

Establishment of a human breast cancer xenograft tumor model in nude mice and analysis of the effect of CSE on breast cancer metastasis in vivo. A total of $19 \mathrm{BALB} / \mathrm{c}$ nude mice (female; age range, 4-6 weeks) were divided into three groups: Blank group (three BALB/c nude mice); CSE expression group (eight $\mathrm{BALB} / \mathrm{c}$ nude mice); and CSE knockdown group (eight BALB/c nude mice). MDA-MB-231 cells $\left(2 \times 10^{6}\right)$ and MDA-MB-231 cells stably transfected with CSE shRNA $\left(2 \times 10^{6}\right)$ were injected into the nude mice of two groups (CSE expression group and CSE knockdown group, respectively) through the tail vein. Physiological saline was injected into nude mice of the blank group. After 4 weeks, the nude mice were sacrificed and the lung tissues were dissected. Hematoxylin and eosin (H\&E) staining of the lung tissues was then performed to further analyze the effect of the expression of CSE on breast cancer metastasis. H\&E staining of lung tissues of nude mice was performed in serial sections (average section area, $1 \mathrm{x} 1 \mathrm{~cm}$ ) of formalin-fixed, paraffin-embedded tissues ( $0.2 \mathrm{~cm}$-thick). Following deparaffinization, the slides were first dipped in the updated xylene for 15 min (twice) and then placed in the updated $100 \%$ ethanol for $5 \mathrm{~min}$ (twice), followed by soaking in $95 \%$ ethanol, $85 \%$ ethanol, $75 \%$ ethanol and double distilled water for 5 min each. The sections were then stained with hematoxylin for $1 \mathrm{~min}$, differentiated with $1 \%$ hydrochloric acid-ethanol for $10 \mathrm{sec}$, and washed with water for $20 \mathrm{sec}$, followed by staining with eosin for $30 \mathrm{sec}$. Finally, the sections were dehydrated with double distilled water, $75 \%$ ethanol, $85 \%$ ethanol, $95 \%$ ethanol and anhydrous ethanol, and images were captured with a microscope (BX43F; Olympus Corporation).

MTS assay. The MDA-MB-231 cells were seeded into 96-well plates at a density of $1 \times 10^{6} / \mathrm{ml}$, and treated with CSE siRNA, the CSE overexpression plasmid, and 0, 5, 10, 20, 30 and $40 \mu \mathrm{M} \mathrm{I157172}$ at $37^{\circ} \mathrm{C}$ for $48 \mathrm{~h}$, respectively. Cell viability was evaluated by determining the number of cells with MTS (Sigma-Aldrich; Merck KGaA), according to the manufacturer's protocol. The assay was performed in triplicate for three independent experiments.

5-ethynyl-2'-deoxyuridine (EdU) assay. The EdU assay was used to examine the effects of the novel CSE inhibitor I157172 on cell proliferation. Briefly, the MDA-MB-231 cells were cultured in 96-well plates at a density of $1 \times 10^{4} /$ well and then exposed to $0,10,20$ and $30 \mu \mathrm{M}$ I157172 (Compound Handing B.V.) for $24 \mathrm{~h}$ at $37^{\circ} \mathrm{C}$. Subsequently, the cells were incubated with $50 \mu \mathrm{m}$ EdU for $2 \mathrm{~h}$ at room temperature, fixed with $4 \%$ formaldehyde for $30 \mathrm{~min}$ at room temperature, incubated with glycine $(2 \mathrm{mg} / \mathrm{ml})$ for $5 \mathrm{~min}$ and treated with $0.5 \%$ Triton $\mathrm{X}-100$ for $10 \mathrm{~min}$ to permeabilize the cells. Following washing with PBS for $5 \mathrm{~min}$, the cells were incubated with 1X Apollo ${ }^{\circledR} 567$ (Guangzhou Ribobio Co., Ltd.) for $30 \mathrm{~min}$ and treated twice with $0.5 \%$ Triton $\mathrm{X}-100$. The DNA was stained with Hoechst 33342 for $30 \mathrm{~min}$ and visualized using fluorescence microscopy. Five groups of cells in the images were randomly selected.

Scratch assay. A scratch assay was used to determine cell migration. The MDA-MB-231 cells were seeded into a 6-well plate and were scraped with a $10-\mu 1$ pipette tip once they reached $\sim 90 \%$ confluence to generate a wound, following which they were rinsed twice with PBS. Subsequently, the cells were transfected with CSE siRNA or the CSE overexpression 
plasmid and were cultured in medium containing 5\% FBS for $24 \mathrm{~h}$ at $37^{\circ} \mathrm{C}$. The distance of wound closure was measured at the beginning of the experiment and after $24 \mathrm{~h}$ using an inverted microscope (IX53; Olympus Corporation). The assay was performed in triplicate.

Transwell assay. A Transwell assay was performed to examine cell migration and invasion as previously described (18). Briefly, for the invasion assay, prior to cell seeding, 24-well Transwell chambers (8- $\mu \mathrm{m}$ pore size; Corning Incorporated) were coated with Matrigel matrix (BD Biosciences). Following this, $5 \times 10^{4}$ cells were suspended in $200 \mu 1$ DMEM (with $1 \%$ FBS) and seeded into the upper chambers, with DMEM with $15 \%$ FBS placed in the lower chambers. For the migration assay, $2.5 \times 10^{4}$ cells were suspended in $200 \mu 1$ DMEM (with $1 \%$ FBS) and seeded into the upper chambers, with DMEM with $15 \%$ FBS placed in the lower chambers. After $24 \mathrm{~h}$, the cells in the upper chambers were treated with 0, 10, 20 and $30 \mu \mathrm{M}$ I157172 or were transfected with CSE siRNA or the CSE overexpression plasmid for $24 \mathrm{~h}$ at $37^{\circ} \mathrm{C}$, and the cells on the upper surface of the membrane were then removed. The migratory and invasive cells attaching to the lower surface of the membrane were fixed with $4 \%$ polyoxymethylene for $30 \mathrm{~min}$ and stained with $0.1 \%$ crystal violet for $15-20 \mathrm{~min}$ at room temperature. Images of the stained cells were captured under an inverted microscope (IX53; Olympus Corporation). Subsequently, the cells were dissolved in $10 \%$ acetic acid and the optical density at $570 \mathrm{~nm}$ was measured using a microplate spectrofluorometer (EnSpire; PerkinElmer, Inc.)

Determination of $\mathrm{H}_{2} \mathrm{~S}$ production. The methylene blue method was used to determine $\mathrm{H}_{2} \mathrm{~S}$ release to assess the effect of $\mathrm{I} 157172$ on the production of $\mathrm{H}_{2} \mathrm{~S}$ in MDA-MB-231 cells. Briefly, the MDA-MB-231 cells $\left(1 \times 10^{6} / \mathrm{ml}\right)$ were seeded into a 6 -well tissue culture plate. After $24 \mathrm{~h}$, the cells were treated with $0,10,20$ and $30 \mu \mathrm{M}$ I157172, with $2 \mathrm{mM}$ L-cysteine and $0.5 \mathrm{mM}$ pyridoxal phosphate for $24 \mathrm{~h}$ at $37^{\circ} \mathrm{C}$. Concurrently, $1 \%(\mathrm{w} / \mathrm{v})$ zinc acetate $(500 \mu \mathrm{l})$ was added to filter papers adhered to the lid of the 6 -well tissue culture plate for $24 \mathrm{~h}$, in order to absorb $\mathrm{H}_{2} \mathrm{~S}$. The filter papers were then placed into tubes containing $0.2 \%(\mathrm{w} / \mathrm{v})$ $\mathrm{N}, \mathrm{N}$-dimethyl-p-phenylenediamine-dihydrochloride dye $(500 \mu 1), 10 \%(\mathrm{w} / \mathrm{v})$ and incubated for $20 \mathrm{~min}$ at room temperature. The absorbance at $670 \mathrm{~nm}$ was subsequently measured. The production of $\mathrm{H}_{2} \mathrm{~S}$ was determined using a standard curve of NaHS (0-1 mM; $\left.\mathrm{R}^{2}, 0.9997\right)$ and presented as nmol/min-1 per $1 \times 10^{6}$ cells. The assay was performed in triplicate.

Statistical analysis. Statistical analyses were performed using SPSS software (version 17.0; SPSS, Inc.). Data are expressed as the mean \pm standard deviation. Differences between groups were analyzed using one-way analysis of variance followed by the Bonferroni post hoc test. $\mathrm{P}<0.05$ was considered to indicate a statistically significant difference.

\section{Results}

Metastasis of human breast cancer is associated with the increased expression of CSE. To investigate the association between the expression of CSE and breast cancer metastasis, the expression levels of CSE in human breast cancer samples were compared with different histological grades and lymph node metastasis. The immunohistochemistry data indicated that the expression of CSE in samples from patients with breast cancer exhibiting lymph node metastasis was higher than that in samples without lymph node metastasis. In addition, the level of CSE in grade III breast cancer tissues was higher than that in grade II tissues (Fig. 1A). The expression levels of CSE and the status of breast cancer molecular classification markers were also analyzed, including estrogen receptor (ER), progesterone receptor (PR), human epidermal growth factor receptor 2(HER2), p53 and Ki-67. The results demonstrated that high expression levels of CSE were negatively associated with an $\mathrm{ER}^{+}, \mathrm{PR}^{+}$and $\mathrm{HER} 2^{+}$status, and positively associated with an ER-/PR/HER2- (triple negative) status, which is a molecular subtype with a high risk of recurrence and metastasis (Fig. 1A). The western blotting and RT-qPCR results also revealed that the levels of CSE in samples from patients with breast cancer exhibiting lymph node metastasis were higher than those in the samples with no lymph node metastasis (Fig. 1B-D). In addition, it was observed that the mRNA and protein expression levels of CSE in early metastatic MDA-MB-231 breast cancer cells were higher than those in non-metastatic MCF7 breast cancer cells (Fig. 1E-G). These data indicated that the increased expression of CSE may act as a promoting factor in breast cancer invasion and metastasis and have a relatively unfavorable prognostic effect during chemotherapy.

Expression of CSEpromotes the growth, migration and invasion of MDA-MB-231 breast cancer cells. In order to investigate the potential role of CSE in breast cancer metastasis, CSE was first knocked down with CSE-specific siRNA in early metastatic MDA-MB-231 breast cancer cells, following which MTS, scratch and Transwell assays were performed. The knockdown of CSE was confirmed via western blot analysis (Fig. 2A). The MTS results revealed that the knockdown of CSE caused the growth inhibition of MDA-MB-231 cells (Fig. 2B). The scratch and Transwell assays revealed that CSE knockdown decreased the migration and invasion rates of MDA-MB-231 cells (Fig. 2C-H). To further confirm the promoting effects of CSE in breast cancer metastasis, a gain-of-function cell model was constructed by transfecting a CSE expression plasmid into MDA-MB-231 cells. The expression of exogenous CSE was confirmed via western blot analysis (Fig. 3A). The MTS, scratch and Transwell assays revealed that the overexpression of CSE promoted cell proliferation (Fig. 3B), migration and invasion (Fig. 3C-H), compared with the vector control. These observations suggested that a high expression of CSE promoted the growth and metastasis of breast cancer cells.

Expression of CSE promotes human breast cancer metastasis in nude mice. Following demonstration of the promotion of CSE on cancer cell metastasis in vitro, whether CSE can promote tumor metastasis in vivo was investigated. A xenograft tumor model was used to assess the metastasis of MDA-MB-231 human breast cancer cells with a high expression of CSE and CSE shRNA stable transfectants of MDA-MB-231 cells in nude mice. As presented in Fig. 4, the rate of lung metastasis was $75 \%$ in nude mice receiving MDA-MB-231 cells expressing CSE, whereas the knockdown of CSE in MDA-MB-231 cells resulted in a significant 
A

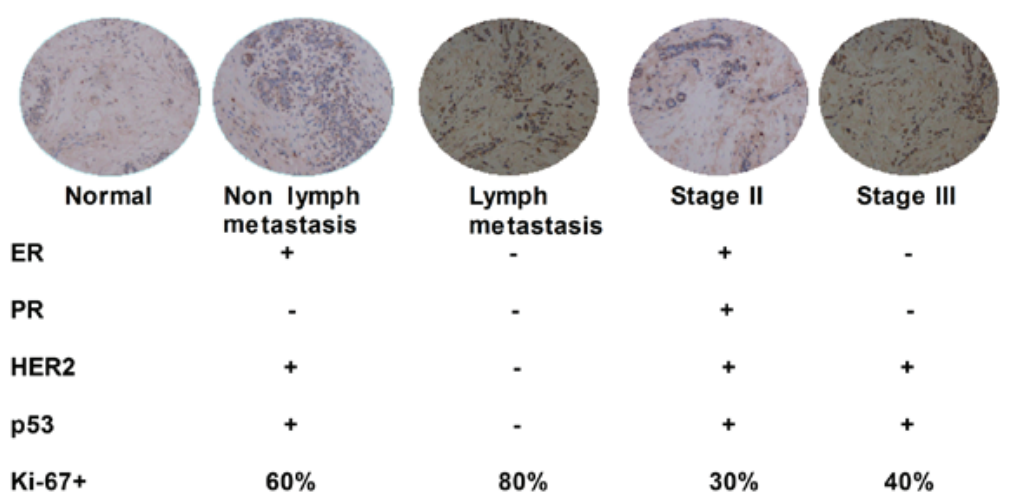

B

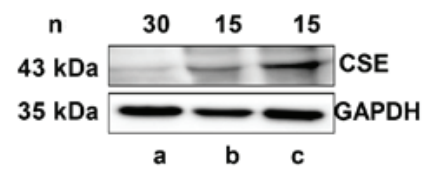

C

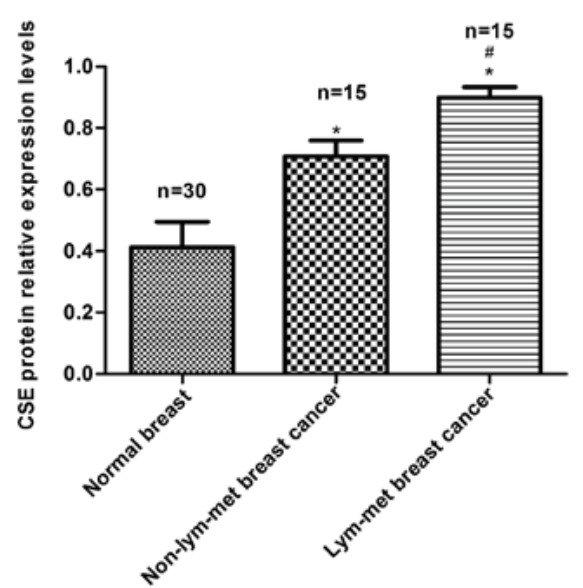

a: Normal breast tissues

b: Non lymph metastasis breast cancer tissues

c: Lymph metastasis breast cancer tissues

D

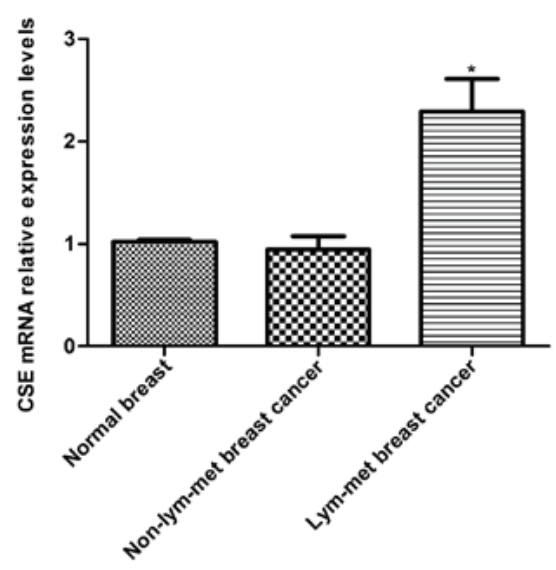

E

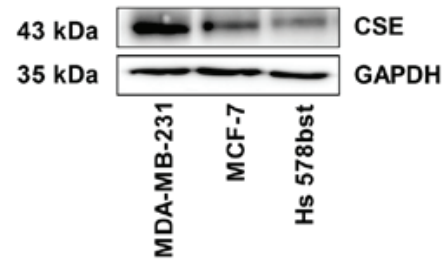

G
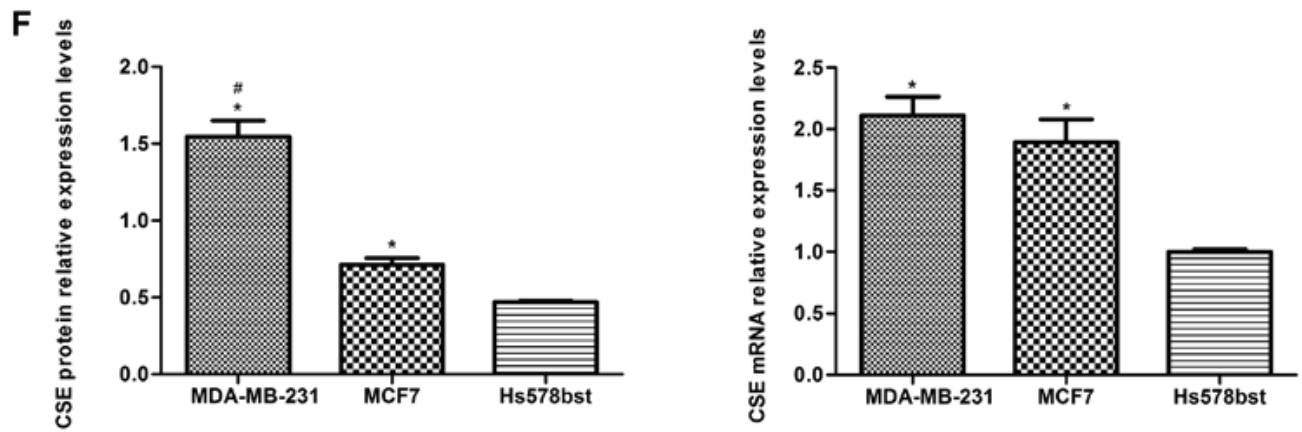

Figure 1. Human breast cancer metastasis is associated with increased expression levels of CSE. (A) Immunohistochemical analysis of expression levels of CSE in breast cancer tissues from 30 human samples comparing receptors, p53, Ki-67, lymph node metastasis and histological grade status (magnification, x200). (B) Western blot analysis of expression levels of CSE in human breast cancer tissues. (C) Quantification of protein levels. "P $<0.05$ vs. normal breast cancer; ${ }^{\#} \mathrm{P}<0.05$ vs. non-lymph node metastatic breast cancer. (D) RT-qPCR analysis of mRNA levels of CSE in human breast cancer tissues. "P<0.05 vs. normal breast cancer. (E) Western blot analysis of expression levels of CSE in human breast cancer cells. (F) Quantification of protein levels. "P<0.05 vs. Hs578bst normal human breast cells; ${ }^{*} \mathrm{P}<0.05$ vs. non-metastatic MCF7 breast cancer cells. (G) RT-qPCR analysis of mRNA levels of CSE in human breast cancer cells. ${ }^{*} \mathrm{P}<0.05$ vs. human normal breast Hs578bst cells. CSE, cystathionine- $\gamma$-lyase; ER, estrogen receptor; PR, progesterone receptor; HER2, human epidermal growth factor receptor 2; RT-qPCR, reverse transcription-quantitative polymerase chain reaction.

decrease in the rate of lung metastases (12.5\%) in nude mice and only led to intravascular tumor thrombus. Collectively, these data indicate that CSE may possess a significant effect on promoting tumor metastasis in breast cancer.
Expression of CSE increases the levels of MMP-2 and $M M P-9$ in MDA-MB-231 cells. Following confirmation of the role of CSE in promoting breast cancer metastasis, the reason why CSE promotes breast cancer metastasis was 
A

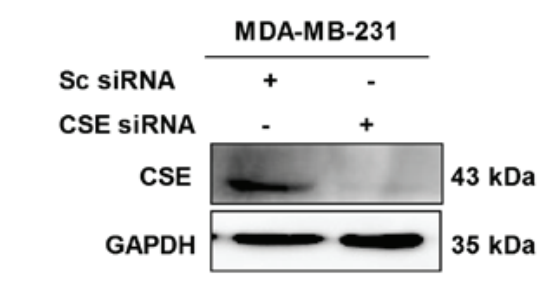

C

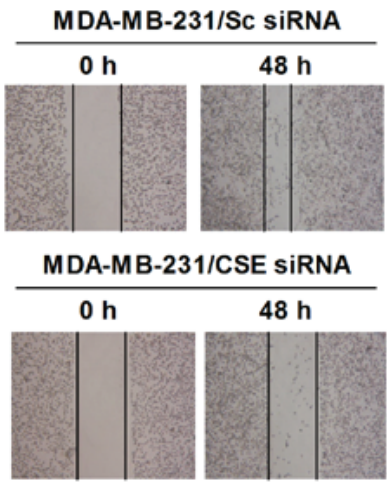

E

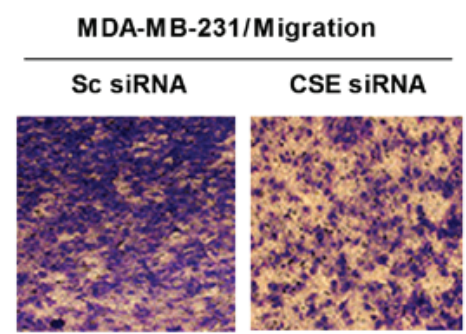

G

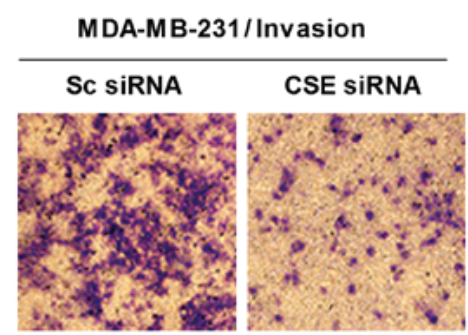

B

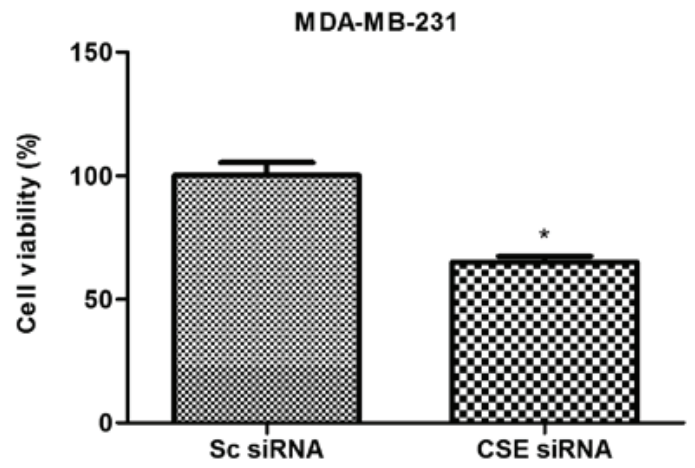

D

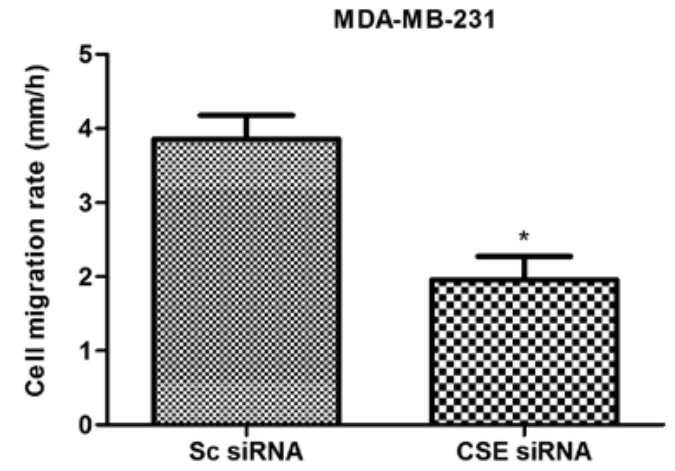

$\mathbf{F}$

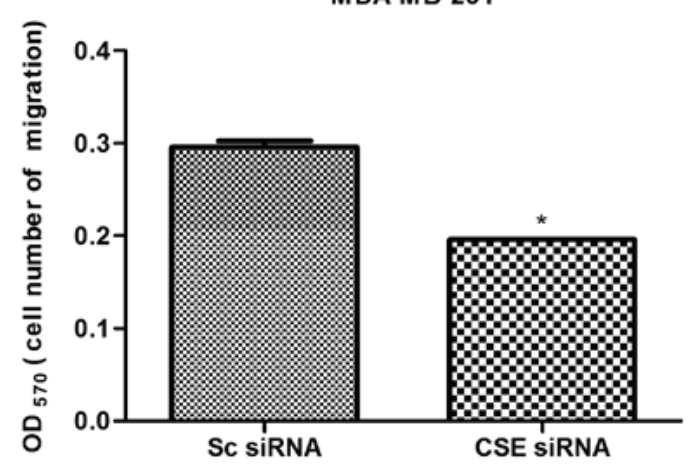

H

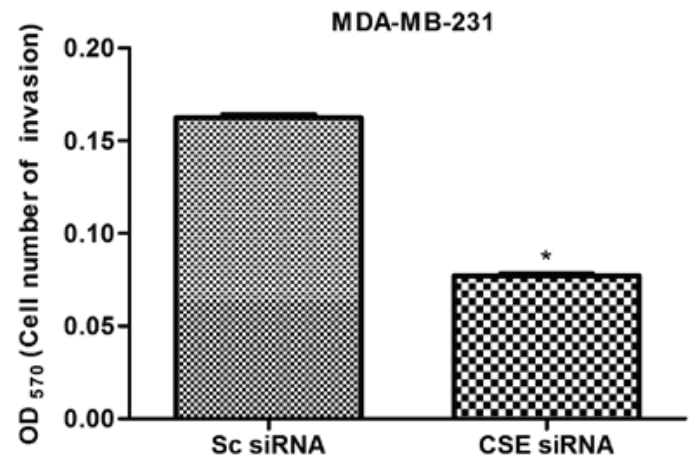

Figure 2. CSE knockdown inhibits the growth, migration and invasion of MDA-MB-231 cells. (A) Western blot assay confirming the knockdown of CSE caused by CSE siRNA. (B) MTS assay to detect the effect of CSE knockdown on cell growth. (C) Scratch assay (magnification, x40) with (D) quantification; (E) Transwell assay (magnification, x 200) with (F) quantification; these assays determined the effect of CSE knockdown on cell migration. ${ }^{*} \mathrm{P}<0.05$ vs. Sc siRNA group. (G) Transwell assay (magnification, x200) with (H) quantification to examine the effect of CSE knockdown on cell invasion. ${ }^{*} \mathrm{P}<0.05$ vs. Sc siRNA group. CSE, cystathionine- $\gamma$-lyase; Sc, scrambled; siRNA, small interfering RNA.

investigated. MMPs secreted by cancer cells can degrade the basement membrane and consequently promote tumor cells to enter the blood circulation, so as to facilitate the diffusion and metastasis to the distal end. Therefore, the effect of the level of CSE on the expression of MMP-2 and MMP-9 in MDA-MB-231 cells was detected. As presented in Fig. 5A and B, the knockdown of CSE distinctly decreased the levels of MMP-2 and MMP-9 in MDA-MB-231 cells, whereas the upregulation of CSE increased the levels of MMP-2 and MMP-9 in the CSE-knockdown MDA-MB-231 cells (Fig. 5C and D). Therefore, it was clear that increased levels of CSE promoted degradation of the basement 
A

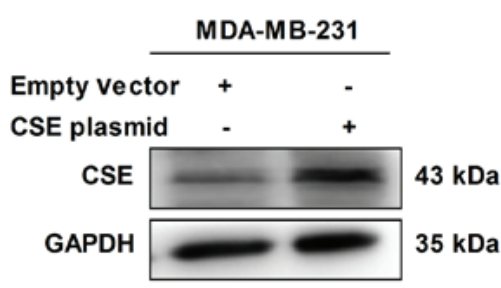

C

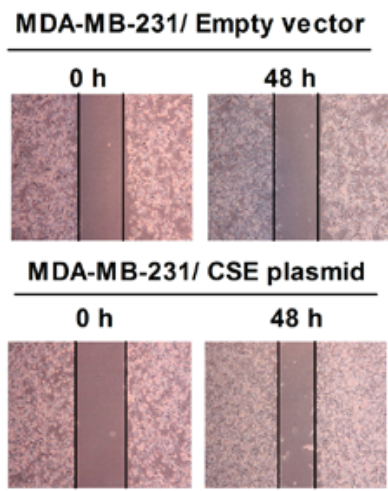

E

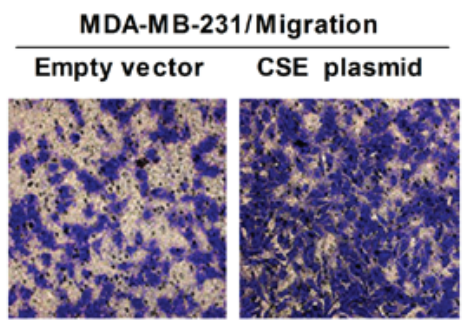

G

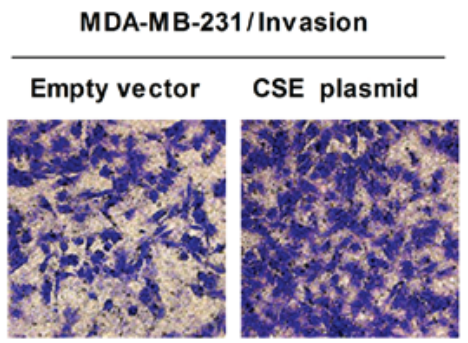

B

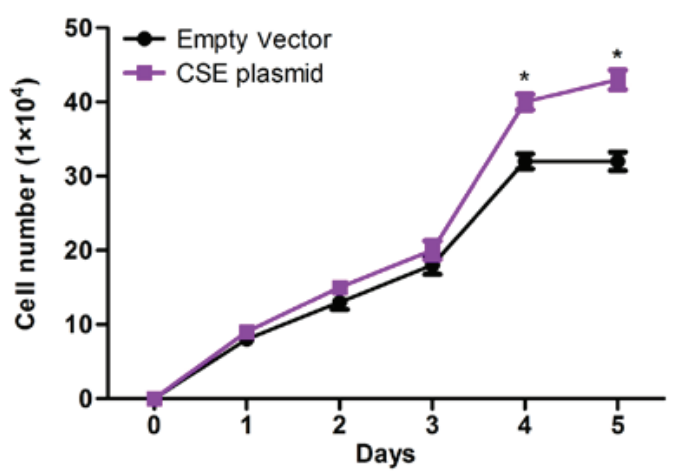

D

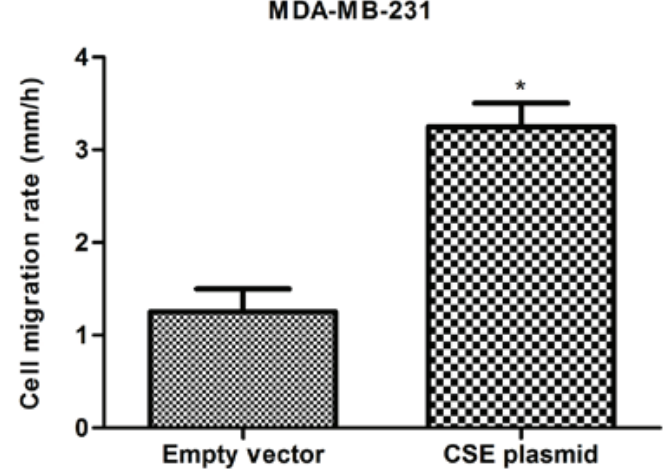

$\mathbf{F}$

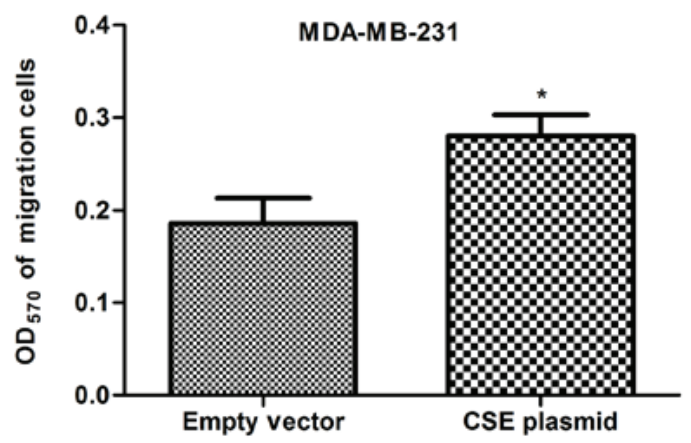

H

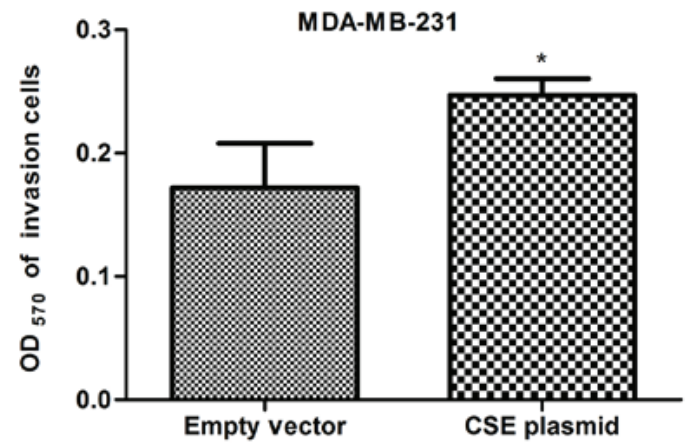

Figure 3. Upregulation of CSE promotes the growth, migration and invasion of MDA-MB-231 cells. (A) Western blot assay confirming the overexpression of CSE caused by the CSE plasmid. (B) Effect of the overexpression of CSE on cell growth. (C) Scratch assay (magnification, x40) with (D) quantification; (E) Transwell assay (magnification, x 200) with (F) quantification; these assays determined the effect on cell migration. (G) Transwell assay (magnification, $\mathrm{x} 200)$ with $(\mathrm{H})$ quantification to determine effects on cell invasion. " $\mathrm{P}<0.05$ vs. empty vector group. CSE, cystathionine- $\gamma$-lyase.

membrane and consequently facilitated the diffusion and metastasis of breast cancer cells.

Expression of CSE promotes the VEGF signaling pathways in MDA-MB-231 cells. Angiogenesis is essential for tumor metastasis, and VEGF, an endothelial cell-specific mitogenic factor, is the most common tumor angiogenesis-stimulating factor. The effect of the expression of CSE on the level of VEGF was investigated in MDA-MB-231 cells. It was demonstrated that the knockdown of CSE significantly decreased the level of VEGF, whereas the upregulation of CSE reversed this (Figs. 6A and B, and 7A and B). In order to 


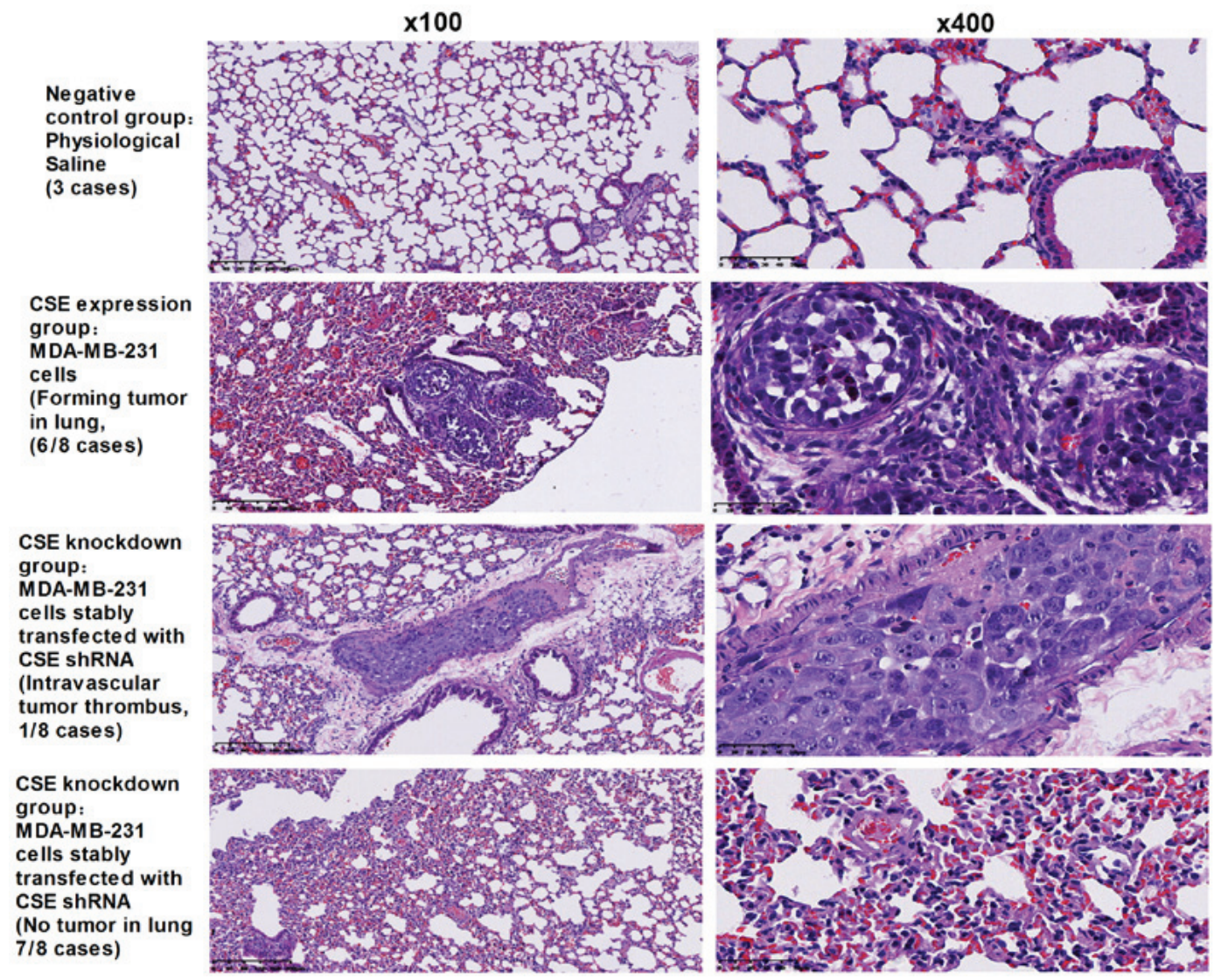

Figure 4. CSE knockdown inhibits human breast cancer metastasis in nude mice. Hematoxylin and eosin staining of lung tissues of nude mice was performed in order to analyze the effect of the expression of CSE on breast cancer metastasis in vivo. The results revealed that the rate of lung metastases was $75 \%$ in nude mice receiving MDA-MB-231 cells with CSE expression. CSE knockdown MDA-MB-231 cells resulted in a decrease of the rate of lung metastases (12.5\%) in nude mice and only led to intravascular tumor thrombus. CSE, cystathionine- $\gamma$-lyase.

A

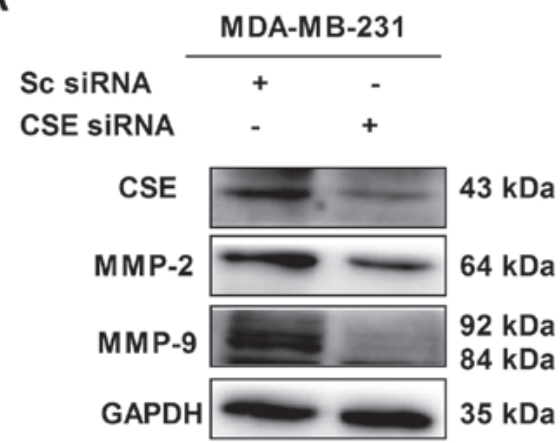

C

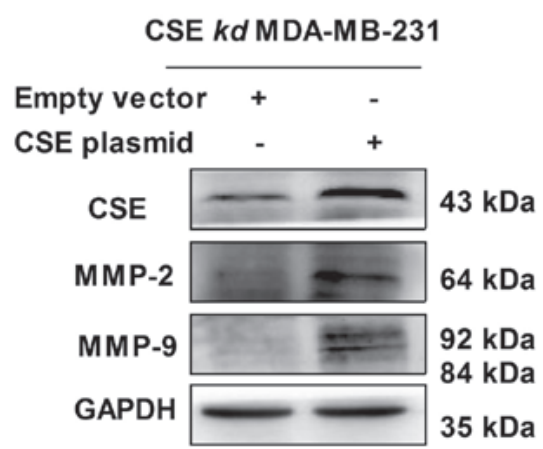

B

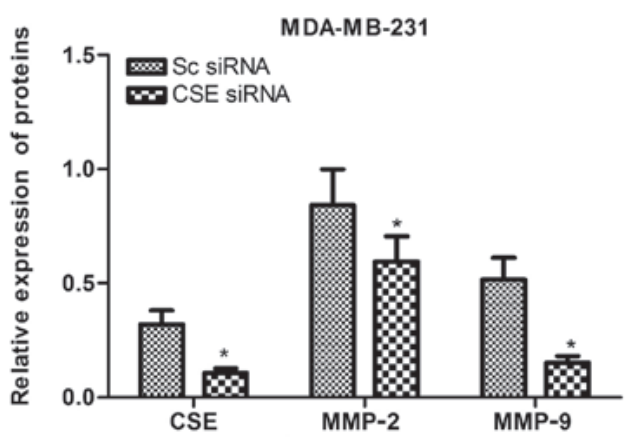

D

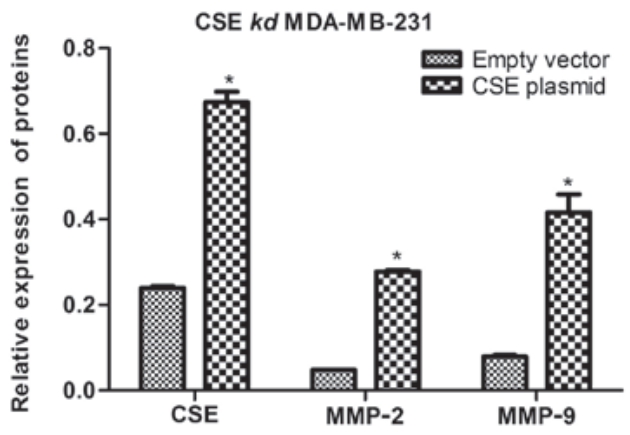

Figure 5. Expression of CSE increases the levels of MMP-2 and MMP-9 in MDA-MB-231 cells. (A) Effect of CSE knockdown on the protein expression of MMP-2 and MMP-9 in MDA-MB-231 cells. (B) Quantification of protein expression following siRNA transfection. ${ }^{*} \mathrm{P}<0.05 \mathrm{vs.} \mathrm{Sc} \mathrm{siRNA} \mathrm{group.} \mathrm{(C)} \mathrm{Effect} \mathrm{of} \mathrm{the} \mathrm{upregulation}$ of CSE on the protein expression of MMP-2 and MMP-9 in CSE knockdown MDA-MB-231 cells. (D) Quantification of protein expression following knockdown

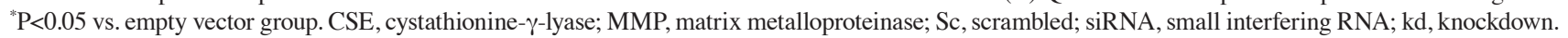



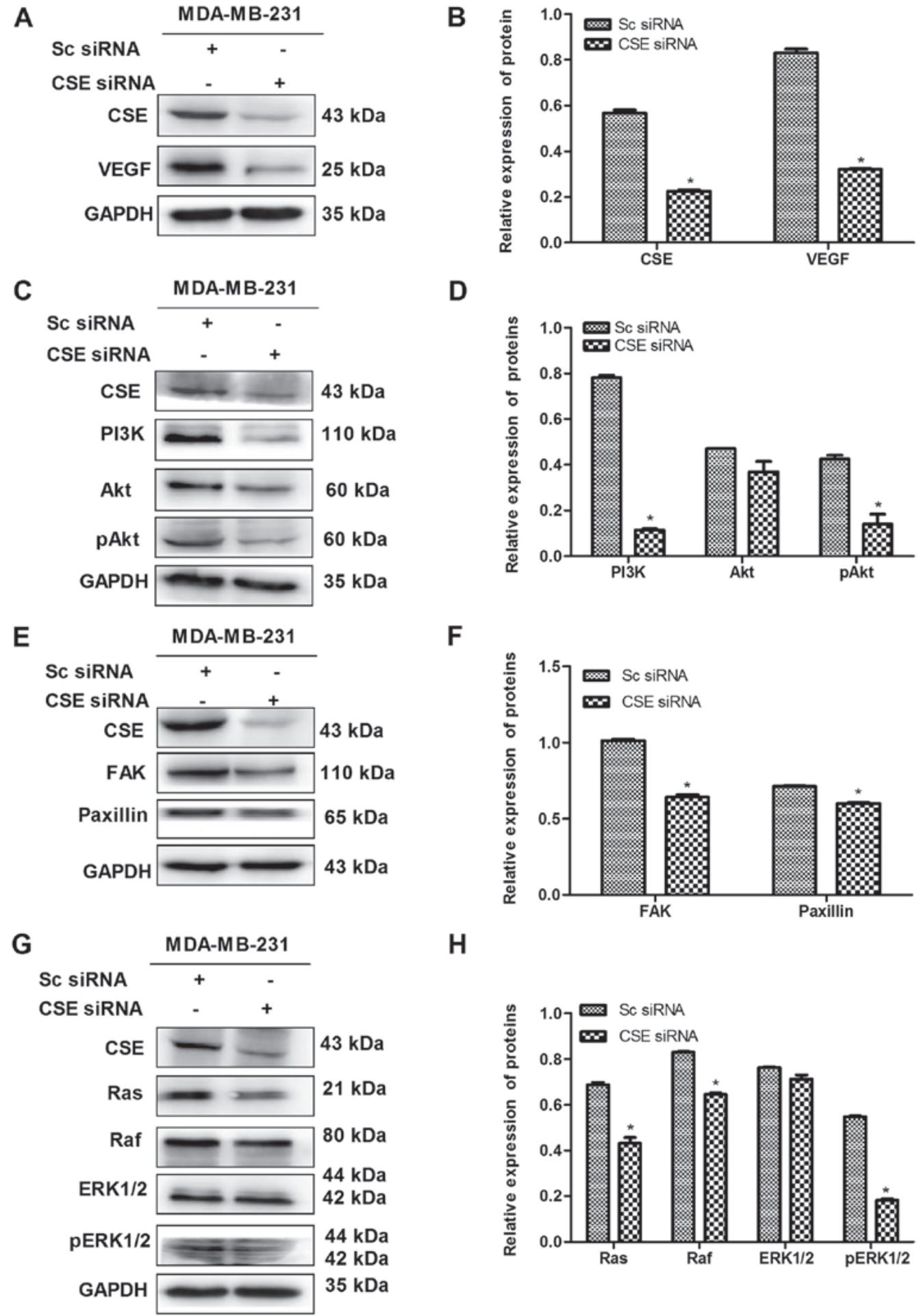

D

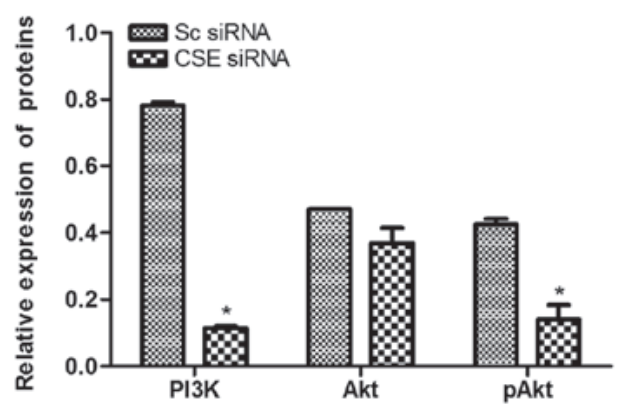

$\mathbf{F}$

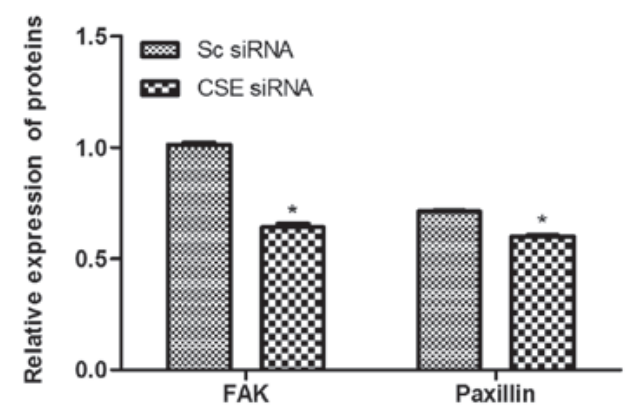

H

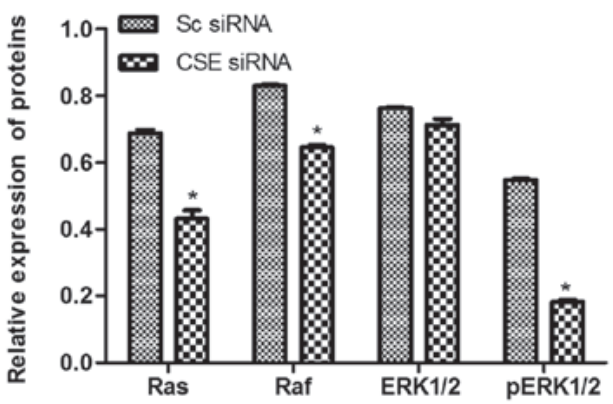

Figure 6. CSE knockdown decreases the expression of VEGF and its downstream pathway in MDA-MB-231 cells. (A) Confirmation of the knockdown of CSE by CSE siRNA and (B) quantification showing the effect of CSE knockdown on the expression of VEGF. (C) Blot and (D) graph showing the effect of CSE knockdown on the PI3K pathway. (E) Blot and (F) graph showing the effect of CSE knockdown on the FAK/paxillin pathway. (G) Blot and (H) graph showing effect of CSE knockdown on the Ras/Raf/ERK1/2 pathway. "P<0.05 vs. Sc siRNA group. CSE, cystathionine- $\gamma$-lyase; Sc, scrambled; siRNA, small interfering RNA; VEGF, vascular endothelial growth factor; PI3K, phosphatidylinositol 3-kinase/protein kinase B; Akt, protein kinase B; pAkt, phosphorylated Akt; FAK, focal adhesion kinase; Ras, rat sarcoma protein; Raf, rapidly accelerated fibrosarcoma; ERK, extracellular signal-regulated protein kinase; pERK, phosphorylated ERK.

further investigate the effect of CSE on the VEGF downstream signaling pathway, the expression of key genes were assessed in MDA-MB-231 cells transfected with CSE siRNA or the CSE overexpression plasmid. As presented in Fig. 6C-H, CSE knockdown significantly decrease the levels of key proteins in the PI3K-AKT pathway (PI3K, Akt and pAkt), FAK-paxillin pathway (FAK and paxillin) and Ras-MAPK pathway (Ras, Raf, ERK1/2 and pERK1/2). However, it was also observed that the upregulation of CSE reversed these effects (Fig. 7C-H). These results suggest that the expression of CSE promoted the VEGF signaling pathway and ultimately advanced the metastasis of breast cancer cells. 
A

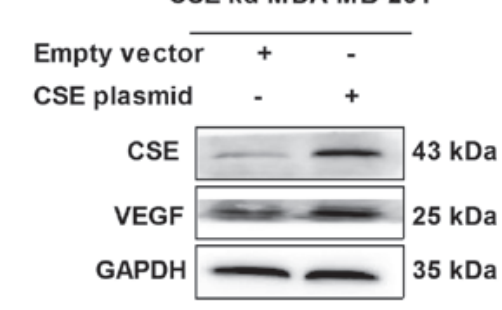

C

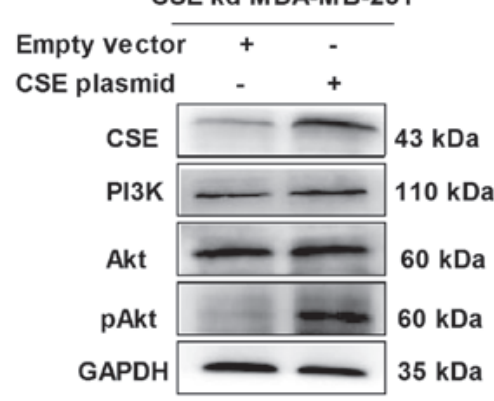

E

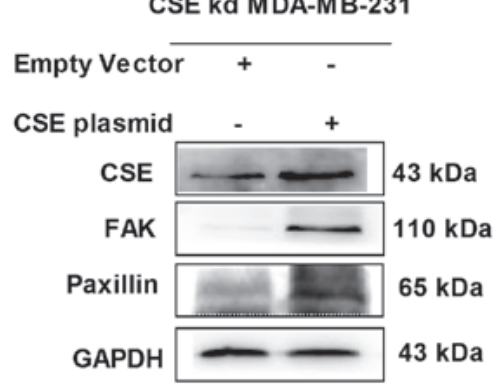

G

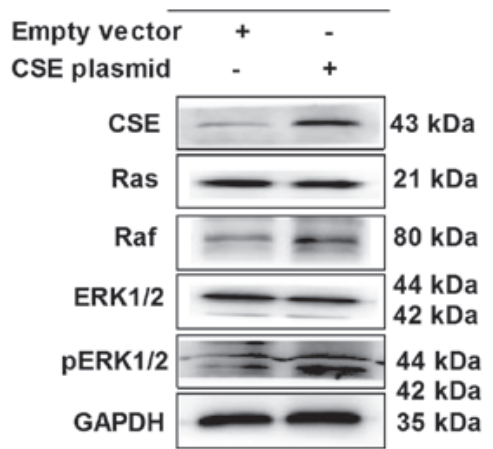

B

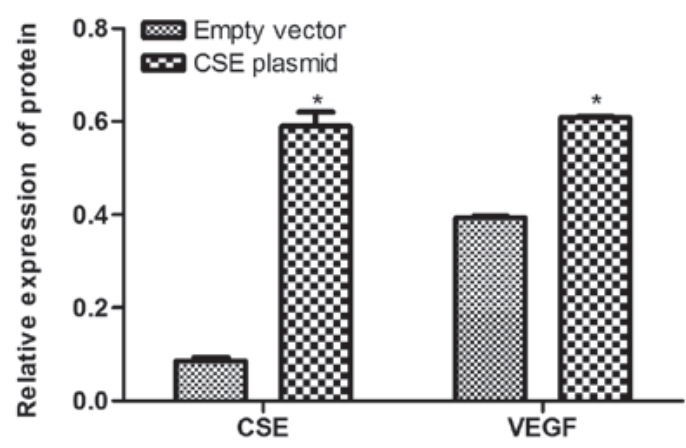

D

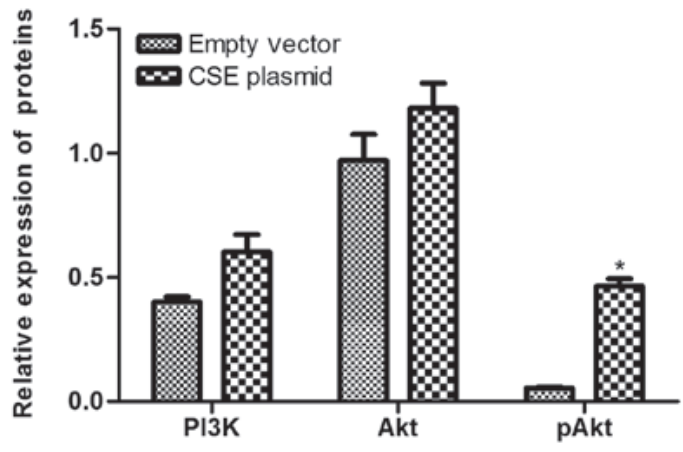

$\mathbf{F}$

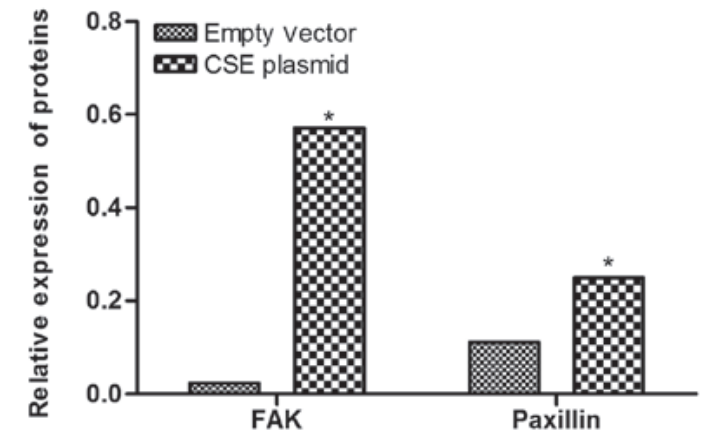

H

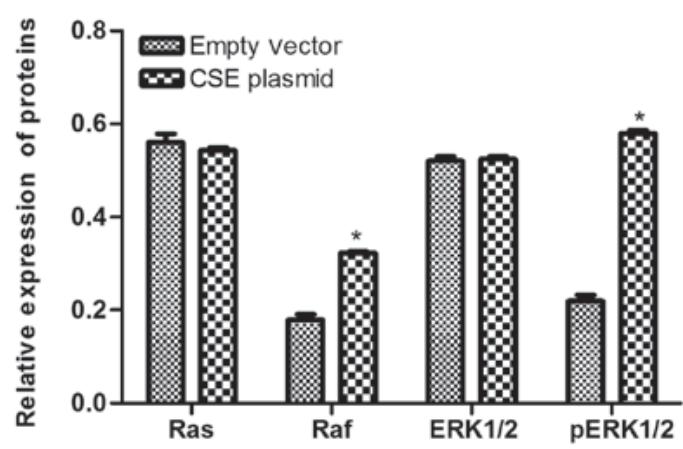

Figure 7. Upregulation of CSE increases the expression levels of VEGF and its downstream pathway in CSE-knockdown MDA-MB-231 cells. (A) Blot and (B) graph confirming of the upregulation of CSE caused by the CSE plasmid and the effect on VEGF. (C) Blot and (D) graph showing the effect of the upregulation of CSE on the PI3K/Akt pathway. (E) Blot and (F) graph showing the effect of the upregulation of CSE on the FAK/paxillin pathway. (G) Blot and (H) graph showing the effect of the upregulation of CSE on the Ras/Raf/ERK1/2 pathway. "P $<0.05$ vs. empty vector group. CSE, cystathionine- $\gamma$-lyase; VEGF, vascular endothelial growth factor; PI3K, phosphatidylinositol 3-kinase/protein kinase B; Akt, protein kinase B; pAkt, phosphorylated Akt; FAK, focal adhesion kinase; Ras, rat sarcoma; Raf, rapidly accelerated fibrosarcoma; ERK, extracellular signal-regulated protein kinase; pERK, phosphorylated ERK; kd, knockdown.

Novel CSE inhibitor 1157172 inhibits the proliferation, migration and invasion of MDA-MB-231 cells. A novel CSE inhibitor I157172 was obtained via virtual screening and its chemical structure is presented in Fig. 8A. The inhibitory activity of I157172 on CSE was confirmed by analysis of the production of $\mathrm{H}_{2} \mathrm{~S}$ and expression of CSE (Fig. 8B-D). MTS, EdU and Transwell assays were performed to evaluate the effects of I157172 on the proliferation, migration and invasion of MDA-MB-231 cells. The data revealed that $\mathrm{I} 157172$ significantly inhibited growth and proliferation in a dose-dependent manner (Fig. 8E-F) and possessed a $20.36 \mu \mathrm{M} \mathrm{IC}_{50}$ value in MDA-MB-231 cells. Decreased migration and invasion rates were observed in MDA-MB-231 cells treated with different concentrations of I157172 (Fig. 8G-J). Taken together, the CSE inhibitor I157172 
A

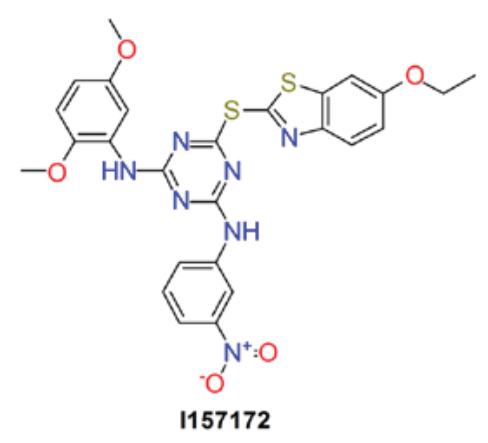

C

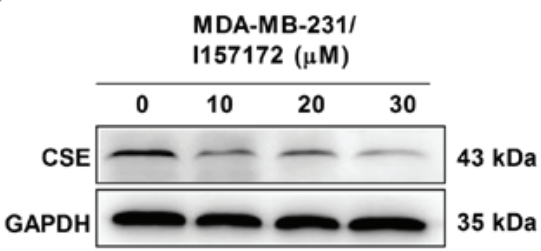

B

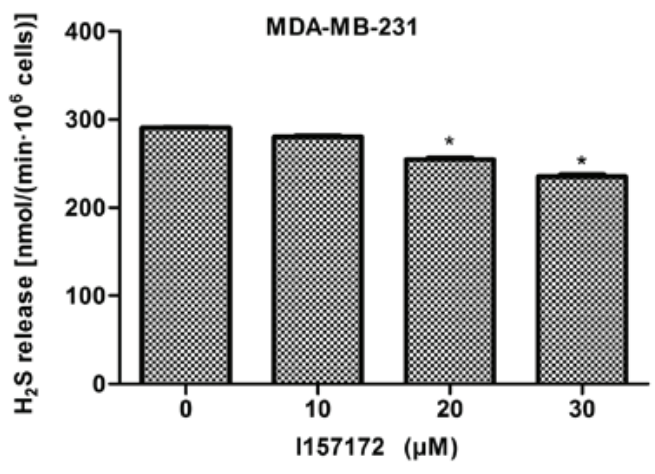

D

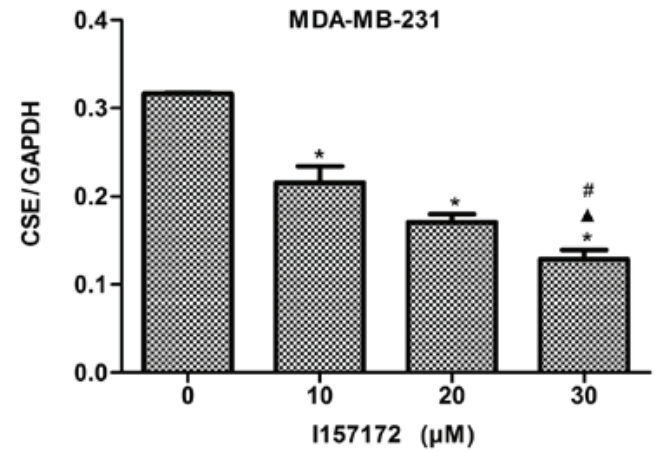

E

F

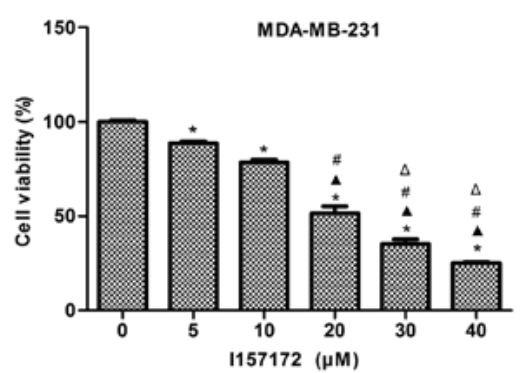

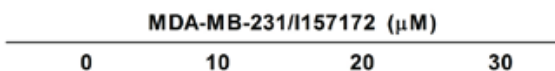

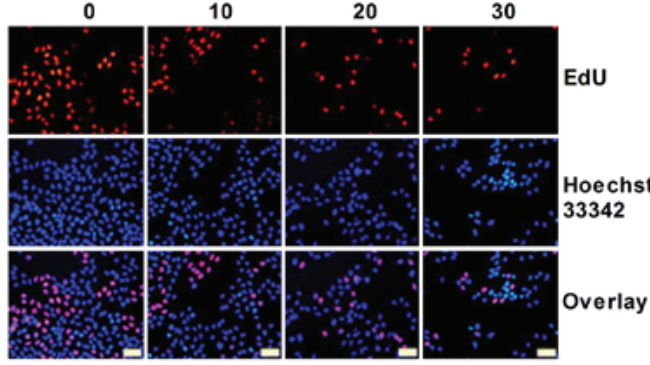

G

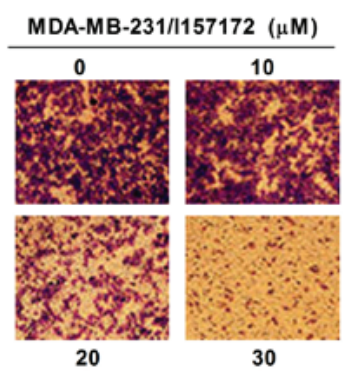

I
H

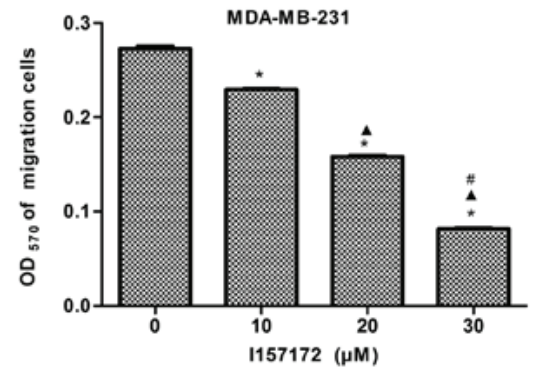

J

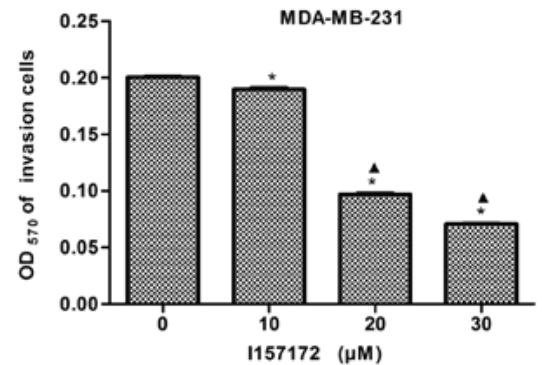

Figure 8. Novel CSE inhibitor I157172 inhibits the proliferation, migration and invasion of MDA-MB-231 cells. (A) Schematic diagram of I157172. (B) A methylene blue assay was used to examine the effect of $\mathrm{I} 157172$ on $\mathrm{H}_{2} \mathrm{~S}$ production in MDA-MB-231 cells. I157172 significantly inhibited the production of $\mathrm{H}_{2} \mathrm{~S}$. "P<0.05 vs. $0 \mu \mathrm{M}$ I157172 group. (C) Effects of different concentrations of I157172 on the protein expression of CSE. (D) Quantification of CSE protein. ${ }^{*} \mathrm{P}<0.05$ vs. $0 \mu \mathrm{M}$ I157172 group; ${ }^{\wedge} \mathrm{P}<0.05$ vs. $10 \mu \mathrm{M} \mathrm{I157172} \mathrm{group;}{ }^{*} \mathrm{P}<0.05$ vs. $20 \mu \mathrm{M}$ I157172 group. (E) Effects of different concentrations of I157172 on cell growth. ${ }^{*} \mathrm{P}<0.05$ vs. $0 \mu \mathrm{M} \mathrm{I} 157172$ group; ${ }^{\wedge} \mathrm{P}<0.05$ vs. $5 \mu \mathrm{M} I 157172$ group; ${ }^{*} \mathrm{P}<0.05$ vs. $10 \mu \mathrm{M}$ I157172 group; ${ }^{\wedge} \mathrm{P}<0.05$ vs. $20 \mu \mathrm{M} \mathrm{I157172} \mathrm{group.} \mathrm{(F)} \mathrm{Effects} \mathrm{of}$ different concentrations of I157172 on cell proliferation (image magnification, x200). (G) Images (magnification, x200) and (H) quantification of the effects of different concentrations of $\mathrm{I} 157172$ on cell migration. ${ }^{*} \mathrm{P}<0.05$ vs. $0 \mu \mathrm{M} \mathrm{I} 157172$ group; ${ }^{\wedge} \mathrm{P}<0.05$ vs. $10 \mu \mathrm{M}$ I157172 group; ${ }^{\#} \mathrm{P}<0.05$ vs. $20 \mu \mathrm{M}$ I157172 group. (I) Images (magnification, $\mathrm{x} 200$ ) and (J) quantification of the effects of different concentrations of I157172 on cell invasion. "P<0.05 vs. $0 \mu \mathrm{M}$ I157172 group; ${ }^{\wedge} \mathrm{P}<0.05$ vs. $10 \mu \mathrm{M} \mathrm{I} 157172$ group; ${ }^{*} \mathrm{P}<0.05$ vs. $20 \mu \mathrm{M}$ I157172 group. CSE, cystathionine- $\gamma$-lyase; EdU, 5-ethynyl-2'-deoxyuridine. 
A

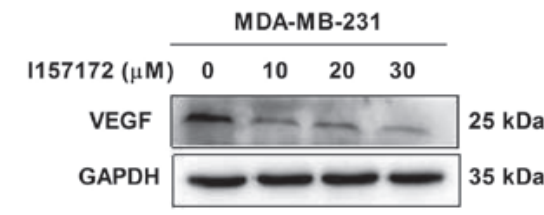

C

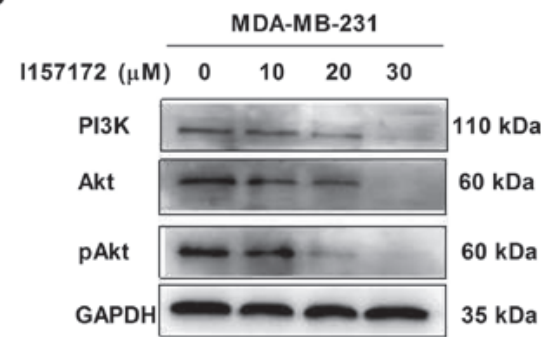

E

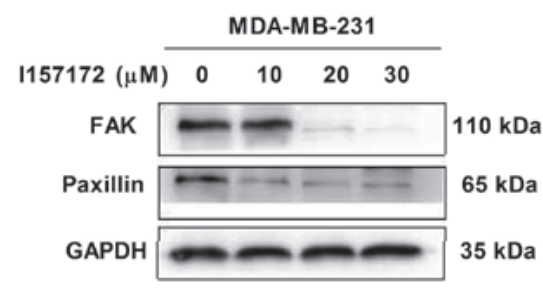

G

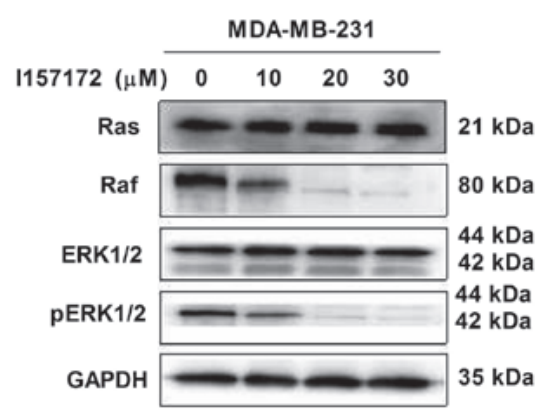

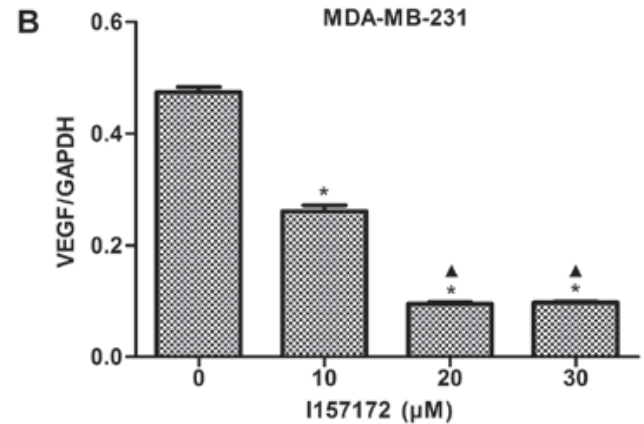

D

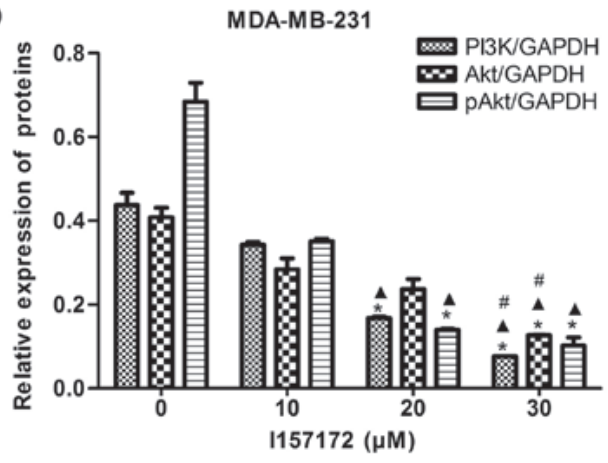

$\mathbf{F}$

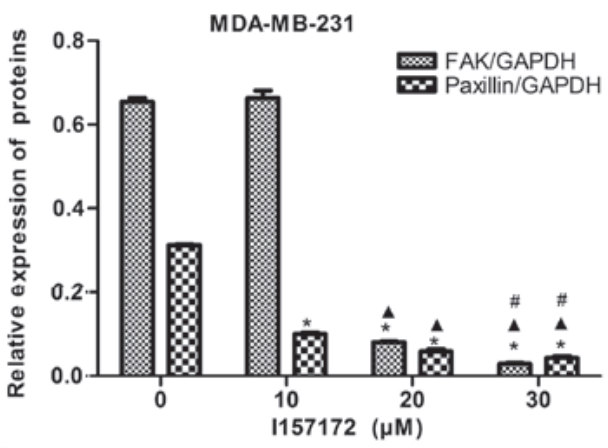

H

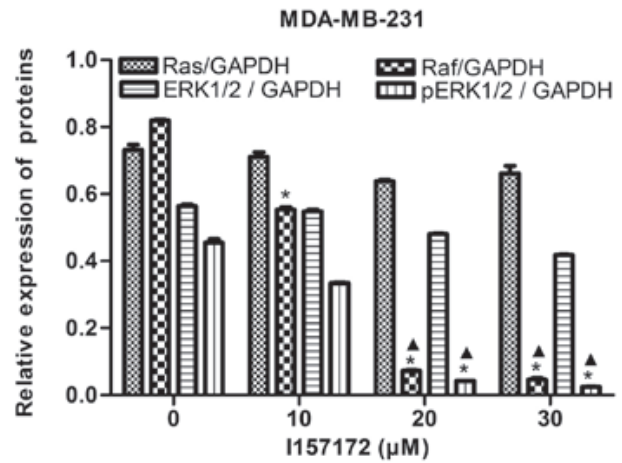

Figure 9. Novel CSE inhibitor I157172 inhibits the VEGF signaling pathway in MDA-MB-231 cells. (A) Blots and (B) graph showing the effect of different concentrations of I157172 on the expression of VEGF. ${ }^{*} \mathrm{P}<0.05$ vs. $0 \mu \mathrm{M} I 157172$ group; ${ }^{\wedge} \mathrm{P}<0.05$ vs. $10 \mu \mathrm{M}$ I157172 group. (C) Blots and (D) graph showing the effect of different concentrations of I157172 on the PI3K/Akt pathway. ${ }^{*} \mathrm{P}<0.05$ vs. $0 \mu \mathrm{M} \mathrm{I} 157172$ group; ${ }^{\wedge} \mathrm{P}<0.05$ vs. $10 \mu \mathrm{M}$ I157172 group; ${ }^{*} \mathrm{P}<0.05$ vs. $20 \mu \mathrm{M}$ I157172 group. (E) Blots and (F) graph showing the effect of different concentrations of I157172 on the FAK/paxillin pathway. ${ }^{*} \mathrm{P}<0.05 \mathrm{vs} .0 \mu \mathrm{M}$ I157172 group; ${ }^{4} \mathrm{P}<0.05$ vs. $10 \mu \mathrm{M}$ I157172 group; ${ }^{*} \mathrm{P}<0.05$ vs. $20 \mu \mathrm{M}$ I157172 group. (G) Blots and (H) graph showing the effect of different concentrations of I157172 on the Ras/Raf/ERK1/2 pathway. " $\mathrm{P}<0.05$ vs. $0 \mu \mathrm{M} \mathrm{I} 157172$ group; ${ }^{\wedge} \mathrm{P}<0.05$ vs. $10 \mu \mathrm{M}$ I157172 group. CSE, cystathionine- $\gamma$-lyase; VEGF, vascular endothelial growth factor; PI3K, phosphatidylinositol 3-kinase; Akt, protein kinase B; FAK, focal adhesion kinase; Ras, rat sarcoma; Raf, rapidly accelerated fibrosarcoma; ERK, extracellular signal-regulated protein kinase; pERK, phosphorylated ERK; pAkt, phosphorylated Akt.

possessed antiproliferative and anti-metastatic activities in the early metastatic MDA-MB-231 breast cancer cells, which further confirmed the role of CSE in breast cancer metastasis.

Novel CSE inhibitor 1157172 inhibits the VEGF signaling pathway in MDA-MB-231 cells. To further confirm the underlying molecular mechanism of CSE in promoting breast cancer metastasis, the effect of novel CSE inhibitor I157172 on the VEGF signaling pathway was investigated in MDA-MB-231 cells. The data revealed that I157172 significantly inhibited the expression levels of VEGF (Fig. 9A and B) and decreased the levels of key proteins, including PI3K, Akt, pAkt,FAK, paxillin, 


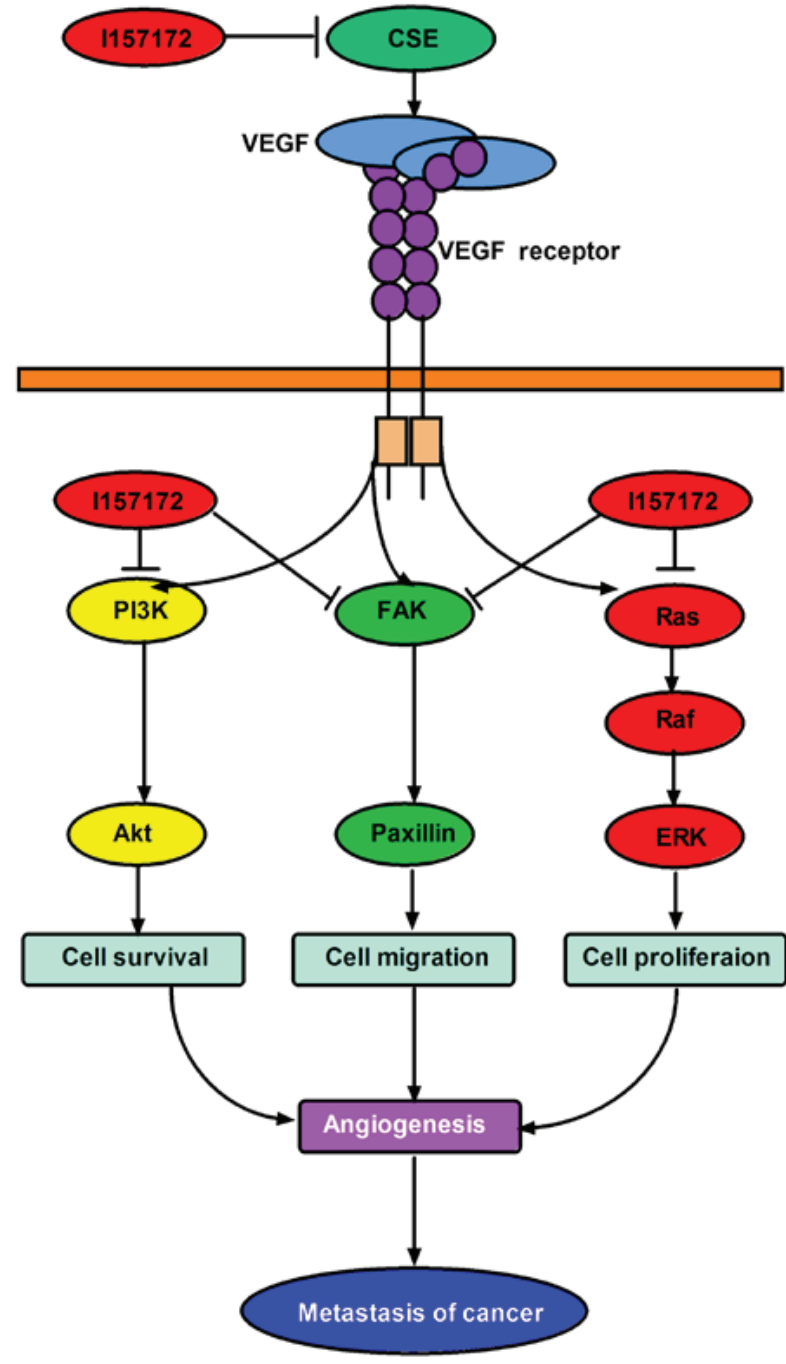

Figure 10. Schematic diagram of the molecular mechanism underlying the promoting roles of the expression of CSE on the progression of breast cancer. CSE, cystathionine- $\gamma$-lyase; VEGF, vascular endothelial growth factor; PI3K, phosphatidylinositol 3-kinase; Akt, protein kinase B; FAK, focal adhesion kinase; Ras, rat sarcoma; Raf, rapidly accelerated fibrosarcoma; ERK extracellular signal-regulated protein kinase.

Raf and pERK1/2, of the VEGF downstream pathway in a dose-dependent manner (Fig. 9C-H). These results suggested that $\mathrm{I157172}$ inhibited the metastasis of MDA-MB-231 cells via downregulating the VEGF signaling pathway, which may be one of the underlying molecular mechanisms by which CSE promotes breast cancer metastasis.

\section{Discussion}

Breast cancer is associated with a high incidence of metastasis, and breast cancer cells preferentially metastasize to the bone and lung via the lymphatic system $(19,20)$, which leads to a poorer patient prognosis. Lymph node metastasis is the most common site for secondary colonization of breast cancer cells, and the likelihood of metastatic spread increases with increasing tumor grade and in hormone receptor-negative cancer.

Metastasis is a complex process and metastatic dissemination represents the main physiopathology of cancer. Approximately $90 \%$ of breast cancer-associated mortality results from the development of metastatic disease (21), therefore, numerous studies have investigated the underlying molecular mechanisms and agents of breast cancer metastasis. For example, Meehan and Welch (22) showed that the anti-metastatic protein breast cancer metastasis suppressor-1 provides important clues regarding the molecular mechanism underlying the cellular processes of the initiation of metastasis (23). Davison et al (24) investigated the antimigration potential of signal transduction inhibitors and co-administered fish oil (24). Although a number of studies have been performed with the aim of identifying underlying molecular mechanisms and agents, metastasis remains the leading cause of mortality in patients with breast cancer.

Previous studies have demonstrated that endogenous $\mathrm{H}_{2} \mathrm{~S}$ produced by CSE, a main enzyme catalyzing the endogenous production of $\mathrm{H}_{2} \mathrm{~S}$, can promote the proliferation of human cancer cells $(14,15)$ and contribute to the angiogenic process (12). Angiogenesis is an important concern in the process of tumor metastasis. Therefore, in the present study, the role of the $\mathrm{CSE} / \mathrm{H}_{2} \mathrm{~S}$ system in breast cancer metastasis was investigated which, to the best of our knowledge, revealed for the first time that CSE may promote the metastasis of breast cancer.

The present study demonstrated that the expression of CSE was higher in samples from patients with breast cancer exhibiting lymph node metastasis than in those with no lymph node metastasis. In addition, higher mRNA and protein levels of CSE were observed in early metastatic MDA-MB-231 breast cancer cells compared with those in non-metastatic MCF7 breast cancer cells. These findings indicate that the metastasis of human breast cancer may be associated with increased expression levels of CSE.

Triple negative breast cancer (TNBC), characterized by invasive clinical behavior, has a propensity to metastasize and establish secondary tumors (25). The targeted treatment of patients with TNBC has been limited due the fact that patients with TNBC do not express any of the three receptors (ER, PR and HER2). The recognition and validation of novel targets is important for the inhibition of metastasis in TNBC. Therefore, in the present study, the roles of the expression of CSE in MDA-MB-231 TNBC cells was investigated. The function of CSE protein in promoting breast cancer metastasis was confirmed in vitro and in vivo. The expression of CSE promoted the growth, migration and invasion of breast cancer cells in vitro. In further examination of in vivo function, it was revealed that CSE knockdown inhibited lung metastasis of MDA-MB-231 in nude mice. It follows that the $\mathrm{CSE} / \mathrm{H}_{2} \mathrm{~S}$ system possesses a function in promoting breast cancer metastasis.

The present study further assessed the effects of the expression of CSE on MMP-2 and MMP-9 and on the VEGF signaling pathway in order to investigate the molecular mechanism underlying the effect of CSE in promoting breast cancer metastasis. MMP-2 and MMP-9, secreted by cancer cells, can degrade the basement membrane and consequently promote tumor cells to enter the blood circulation, facilitating diffusion and metastasis to the distal end (26). The results of the present study suggested that the expression of CSE increased the levels of MMP-2 and MMP-9 in early metastatic breast cancer cells. VEGFs constitute a sub-family of growth factors 
that stimulate the growth of new blood vessels. Vascular VEGFs are important signaling proteins involved in vasculogenesis and angiogenesis. VEGF is key mediator of angiogenesis that is crucial for the development and metastasis of tumors (27), which is essential for tumor metastasis. In the present study, it was revealed that the expression of CSE distinctly decreased the levels of VEGF and inhibited its downstream pathway.

Based on the function of CSE protein in breast cancer metastasis, a novel CSE inhibitor I157172 was obtained via virtual screening, and it was revealed that I157172 possessed antiproliferative and anti-metastatic activities in early metastatic MDA-MB-231 breast cancer cells, which further confirmed the role of CSE in breast cancer metastasis. In addition, I157172 downregulated the VEGF signaling pathway which further confirmed the mechanism of CSE in promoting breast cancer metastasis.

In conclusion, the increased expression levels of CSE appeared to promote the metastasis of human breast cancer via the VEGF signaling pathway, and the novel CSE inhibitor I157172 inhibited the metastasis of early metastatic breast cancer cells via downregulating the VEGF signaling pathway (Fig. 10). This provides novel targets and agents for the treatment and prognosis of breast cancer. Future experiments aim to continue to examine the mechanism of CSE in breast cancer and the anti-breast cancer effect and mechanism of I157172 in vivo, in order to promote the development of novel anti-breast cancer drugs.

\section{Acknowledgements}

Not applicable.

\section{Funding}

The authors would like to acknowledge the financial assistance provided by the Key Science and Technology Fund of Henan Province in China (grant no. 162300410035) and the Henan Province University Science and Technology Innovation Team (grant no. 16IRTSTHN019).

\section{Availability of data and materials}

All data generated or analyzed during this study are included in this published article.

\section{Authors' contributions}

TW and XS conceived and designed the experiments. LW and HS performed the experiments. LW, HS, YL, WZ, XD and ML analyzed the data and produced the figures. LW wrote and proofread the paper. TW and XS revised the manuscript. All authors read and approved the manuscript and agree to be accountable for all aspects of the research in ensuring that the accuracy or integrity of any part of the work are appropriately investigated and resolved.

\section{Ethics approval and consent to participate}

The present study was approved by the Ethics Committee at the Medical School, Henan University (Kaifeng, China).

\section{Patient consent for publication}

Not applicable.

\section{Competing interests}

The authors declare that they have no competing interests.

\section{References}

1. Davidson B, Konstantinovsky S, Nielsen S, Dong HP, Berner A, Vyberg M and Reich R: Altered expression of metastasis-associated and regulatory molecules in effusions from breast cancer patients: A novel model for tumor progression. Clin Cancer Res 10: 7335-7346, 2004.

2. Hagemann T, Robinson SC, Schulz M, Trümper L, Balkwill FR and Binder C: Enhanced invasiveness of breast cancer cell lines upon co-cultivation with macrophages is due to TNF- $\alpha$ dependent up-regulation of matrix metalloproteases. Carcinogenesis 25: 1543-1549, 2004

3. Hiscox S, Jordan NJ, Jiang W, Harper M, McClelland R, Smith C and Nicholson RI: Chronic exposure to fulvestrant promotes overexpression of the c-Met receptor in breast cancer cells: Implications for tumour-stroma interactions. Endocr Relat Cancer 13: 1085-1099, 2006.

4. Pecorino L: Molecular Biology of Cancer. Oxford University Press, Oxford, p400, 2005.

5. Siegel RL, Miller KD and Jemal A: Cancer statistics, 2016. CA Cancer J Clin 66: 7-30, 2016.

6. Papapetropoulos A, Pyriochou A, Altaany Z, Yang G, Marazioti A, Zhou Z, Jeschke MG, Branski LK, Herndon DN, Wang R, et al: Hydrogen sulfide is an endogenous stimulator of angiogenesis. Proc Natl Acad Sci USA 106: 21972-21977, 2009.

7. Chen DB, Feng L, Hodges JK, Lechuga TJ and Zhang H: Human trophoblast-derived hydrogen sulfide stimulates placental artery endothelial cell angiogenesis. Biol Reprod 97: 478-489, 2017.

8. Wang R: Hydrogen sulfide: The third gasotransmitter in biology and medicine. Antioxid Redox Signal 12: 1061-1064, 2010.

9. Kimura Y, Goto Y and Kimura H: Hydrogen sulfide increases glutathione production and suppresses oxidative stress in mitochondria. Antioxid Redox Signal 12: 1-13, 2010.

10. Sheng J, Shim W, Wei H, Lim SY, Liew R, Lim TS, Ong BH, Chua YL and Wong P: Hydrogen sulphide suppresses human atrial fibroblast proliferation and transformation to myofibroblasts. J Cell Mol Med 17: 1345-1354, 2013.

11. Popov D: An outlook on vascular hydrogen sulphide effects, signalling, and therapeutic potential. Arch Physiol Biochem 119: 189-194, 2013.

12. Katsouda A,BibliSI,Pyriochou A,Szabo Cand Papapetropoulos A: Regulation and role of endogenously produced hydrogen sulfide in angiogenesis. Pharmacol Res 113: 175-185, 2016.

13. Sbodio JI, Snyder SH and Paul BD: Regulators of the transsulfuration pathway. Br J Pharmacol 176: 583-593, 2019.

14. Yin P, Zhao C, Li Z, Mei C, Yao W, Liu Y, Li N, Qi J, Wang L, Shi Y, et al: Sp1 is involved in regulation of cystathionine $\gamma$-lyase gene expression and biological function by PI3K/Akt pathway in human hepatocellular carcinoma cell lines. Cell Signal 24: 1229-1240, 2012.

15. Cai WJ, Wang MJ, Ju LH, Wang C and Zhu YC: Hydrogen sulfide induces human colon cancer cell proliferation: Role of Akt, ERK and p21. Cell Biol Int 34: 565-572, 2010.

16. You J, Shi X, Liang H, Ye J, Wang L, Han H, Fang H, Kang W, Wang $\mathrm{T}$, Han $\mathrm{H}$, et al: Cystathionine- $\gamma$-lyase promotes process of breast cancer in association with STAT3 signaling pathway. Oncotarget 8: 65677-65686, 2017.

17. Fendri A, Kontos CK, Khabir A, Mokdad-Gargouri R, Ardavanis A and Scorilas A: Quantitative analysis of BCL2 mRNA expression in nasopharyngeal carcinoma: An unfavorable and independent prognostic factor. Tumour Biol 31: 391-399, 2010.

18. Nitti M, Piras S, Marinari UM, Moretta L, Pronzato MA and Furfaro AL: HO-1 Induction in Cancer Progression: A Matter of Cell Adaptation. Antioxidants 6: 29, 2017.

19. Cunnick GH, Jiang WG, Douglas-Jones T, Watkins G, Gomez KF, Morgan MJ, Subramanian A, Mokbel K and Mansel RE: Lymphangiogenesis and lymph node metastasis in breast cancer. Mol Cancer 7: 23, 2008. 
20. Fidler IJ: The pathogenesis of cancer metastasis: The 'seed and soil' hypothesis revisited. Nat Rev Cancer 3: 453-458, 2003.

21. Lambert AW, Pattabiraman DR and Weinberg RA: Emerging biological principles of metastasis. Cell 168: 670-691, 2017.

22. Meehan WJ and Welch DR: Breast cancer metastasis suppressor 1 : Update. Clin Exp Metastasis 20: 45-50, 2003.

23. Zhang Y, Ye L, Tan Y, Sun P, Ji K and Jiang WG: Expression of breast cancer metastasis suppressor-1, BRMS-1, in human breast cancer and the biological impact of BRMS-1 on the migration of breast cancer cells. Anticancer Res 34: 1417-1426, 2014.

24. DavisonZ,NicholsonRI,Hiscox S and HeardCM:Co-administration of fish oil with signal transduction inhibitors has anti-migration effects in breast cancer cell lines, in vitro. Open Biochem J 12: 130-148, 2018.
25. Jitariu AA, Cîmpean AM, Ribatti D and Raica M: Triple negative breast cancer: The kiss of death. Oncotarget 8: 46652-46662, 2017.

26. Liu H, Zeng Z, Wang S, Li T, Mastriani E, Li QH, Bao HX, Zhou YJ, Wang X, Liu Y, et al: Main components of pomegranate, ellagic acid and luteolin, inhibit metastasis of ovarian cancer by down-regulating MMP2 and MMP9. Cancer Biol Ther 18: 990-999, 2017.

27. Carmeliet P: VEGF as a key mediator of angiogenesis in cancer. Oncology 69 (Suppl 3): 4-10, 2005.

(i) () $($ This work is licensed under a Creative Commons cc) Attribution-NonCommercial-NoDerivatives 4.0 International (CC BY-NC-ND 4.0) License. 